\title{
Association of APOE Genotype With Heterogeneity of Cognitive Decline Rate in Alzheimer Disease
}

Jing Qian, PhD, Rebecca A. Betensky, PhD, Bradley T. Hyman, MD, PhD, and Alberto Serrano-Pozo, MD, PhD Neurology ${ }^{\circledR}$ 2021;96:e2414-e2428. doi:10.1212/WNL.0000000000011883
Correspondence Dr. Serrano-Pozo aserrano1@ mgh.harvard.edu

\begin{abstract}
Objective

To test the hypothesis that the APOE genotype is a significant driver of heterogeneity in Alzheimer disease $(\mathrm{AD})$ clinical progression, which could have important implications for clinical trial design and interpretation.
\end{abstract}

\section{Methods}

We applied novel reverse-time longitudinal models to analyze the trajectories of Clinical Dementia Rating Sum of Boxes (CDR-SOB) and Mini-Mental State Examination (MMSE) scores - 2 common outcome measures in $\mathrm{AD}$ clinical trials - in 1,102 autopsy-proven $\mathrm{AD}$ cases (moderate/frequent neuritic plaques and Braak tangle stage III or greater) from the National Alzheimer's Coordinating Center Neuropathology database resembling participants with mild to moderate $\mathrm{AD}$ in therapeutic clinical trials.

\section{Results}

$A P O E \& 4$ carriers exhibited $\approx 1.5$ times faster CDR-SOB increase than APOE $\varepsilon 3 / \varepsilon 3$ carriers (2.12 points per year vs 1.44 points per year) and $\approx 1.3$ times faster increase than APOE $\varepsilon 2$ carriers ( 1.65 points per year), whereas $A P O E \varepsilon 2$ vs $A P O E \varepsilon 3 / \varepsilon 3$ difference was not statistically significant. $A P O E \& 4$ carriers had $\approx 1.1$ times faster MMSE decline than $A P O E \varepsilon 3 / \varepsilon 3$ carriers $(-3.45$ vs -3.03 points per year $)$ and $\approx 1.4$ times faster decline than $A P O E \varepsilon 2$ carriers $(-2.43$ points per year), whereas $A P O E \varepsilon 2$ carriers had $\approx 1.2$ times slower decline than $A P O E \varepsilon 3 / \varepsilon 3$ carriers $(-2.43$ vs -3.03 points per year). These findings remained largely unchanged after controlling for the effect of $\mathrm{AD}$ neuropathologic changes on the rate of cognitive decline and for the presence and severity of comorbid pathologies.

\section{Conclusion}

Compared to the $A P O E \varepsilon 3 / \varepsilon 3$ reference genotype, the $A P O E \varepsilon 2$ and $\varepsilon 4$ alleles have opposite (slowing and accelerating, respectively) effects on the rate of cognitive decline, which are clinically relevant and largely independent of the differential $A P O E$ allele effects on $A D$ and comorbid pathologies. Thus, $A P O E$ genotype contributes to the heterogeneity in rate of clinical progression in $\mathrm{AD}$. 


\section{Glossary}

$\mathbf{A} \beta=\beta$-amyloid $\mathbf{A D}=$ Alzheimer disease $; \mathrm{ADC}=$ Alzheimer Disease Center ADNC $=$ Alzheimer disease neuropathological changes; $\mathbf{B I C}=$ Bayesian information criterion; CAA = cerebral amyloid angiopathy; CDR-SOB = Clinical Dementia Rating Sum of Boxes; CERAD = Consortium to Establish a Registry of Alzheimer's Disease; $\mathbf{C I}=$ confidence interval; HScl = hippocampal sclerosis; LB = Lewy bodies; MMSE = Mini-Mental State Examination; NACC = National Alzheimer's Coordinating Center; NFT = neurofibrillary tangle; NP = neuritic plaque; ROSMAP $=$ Religious Orders Study and Rush Memory and Aging Project; TDP-43 = transactive response DNA-binding protein 43kDa; UDS = Uniform Data Set.

One milestone in Alzheimer disease $(\mathrm{AD})$ clinical trials has been the incorporation of PET imaging and CSF biomarkers to exclude $\mathrm{AD}$ mimics and even design secondary prevention trials for participants with preclinical AD. ${ }^{1}$ However, trial success still depends on detecting a treatment vs placebo change in cognitive decline rate, and this is hampered by the substantial variability in rate of clinical progression among participants. One potential contributor to this heterogeneity is the $A P O E$ genotype, given the opposing effects of the $A P O E \varepsilon 4$ and $\varepsilon 2$ alleles on $\mathrm{AD}$ risk, age at symptom onset, and $\mathrm{AD}$ neuropathologic changes (ADNC). ${ }^{2-5}$ However, prior longitudinal clinical studies after symptom onset have reported conflicting results-accelerating, ${ }^{6-9}$ neutral, ${ }^{10-12}$ and slowing effects ${ }^{13-15}$ for $A P O E \& 4$ vs slowing effects for $A P O E$ $\varepsilon 2^{16-18}$ - likely due, at least in part, to the suboptimal accuracy of a clinically based $\mathrm{AD}$ diagnosis. ${ }^{19,20}$ Another proposed driver is the co-occurrence of $\geq 2$ brain pathologies, ${ }^{21}$ each of which could independently contribute to cognitive impairment and could be influenced by the $A P O E$ genotype. ${ }^{22-24}$

We tested the hypothesis that the APOE alleles differentially affect the cognitive decline rate in an autopsy-proven clinical trial-eligible $\mathrm{AD}$ sample. We circumvented the limitations of prior clinical studies by (1) selecting a National Alzheimer's Coordinating Center (NACC) sample with sufficient ADNC to warrant enrollment in current biomarker-based therapeutic clinical trials, (2) applying novel reverse-time longitudinal models to link autopsy findings with cognitive trajectories during life, and (3) controlling for the effects of ADNC on cognitive decline rate and for comorbid pathologies.

\section{Methods}

\section{Standard Protocol Approvals, Registrations, and Patient Consents}

As determined by the University of Washington Human Subjects Division, the NACC database itself is exempt from Institutional Review Board review and approval because it does not involve human participants, as defined by federal and state regulations. However, all contributing Alzheimer Disease Centers (ADCs) are required to obtain informed consent from their participants and to maintain their own separate Institutional Review Board review and approval from their institution before submitting data to NACC.

\section{Inclusion and Exclusion Criteria}

The NACC study is a multicenter longitudinal cohort study conducted in the $\geq 30 \mathrm{ADCs}$ across the United States. Briefly, participants undergo baseline and annual follow-up visits with demographics and standard motor, behavioral, functional, and neuropsychological evaluations collected in a Uniform Data Set (UDS) ${ }^{25,26}$ Participants can donate their brain on death for research purposes, including a standardized neuropathologic evaluation. ${ }^{27}$ The NACC Neuropathology database was interrogated for UDS visits conducted between September 2005 and November 2018. Inclusion criteria included age at death $\geq 50$ years and last visit $<2$ years from the time of death. Exclusion criteria were unknown $A P O E$ genotype, $A P O E \varepsilon 2 / \varepsilon 4$ genotype (due to the small number of cases and presumed cancellation of $A P O E \& 2$ and $A P O E \& 4$ opposite effects), a primary neuropathologic diagnosis other than $\mathrm{ADNC}$, and cognitive impairment attributed to medical illness, medications, or alcohol. To mimic the scenario of a clinical trial with biomarker-based enrollment of participants, we excluded those with none/sparse neuritic plaques (NP) at postmortem examination because they would have had a negative baseline amyloid PET scan before enrollment. ${ }^{28}$ Similarly, to resemble a therapeutic rather than preventive design, we included only those with a Braak neurofibrillary tangle (NFT) stage III or higher because individuals with limbic (III/IV) or isocortical (V/ VI) Braak NFT stages would have had tau PET scans demonstrating limbic and cortical tau deposits. ${ }^{29}$ Our prior inverse probability-weighting analyses on the NACC Neuropathology database demonstrated little impact of potential autopsy-related selection bias in clinicopathologic correlations. ${ }^{30}$

\section{Data Collection}

Data collected included (1) demographic variables (age at each visit and at death, sex, years of education, and length of follow-up), (2) APOE genotype, (3) neuropsychological scores at each visit (Clinical Dementia Rating Sum of Boxes [CDR-SOB; CDR Dementia Staging Instrument], MiniMental State Examination [MMSE], digit span forward and backward, Trail Making Tests A and B, Wechsler Adult Intelligence Scale Digit-Symbol Substitution Test, logical memory immediate and delayed recall, semantic fluency [animals and vegetables in 1 minute], and Boston Naming Test), and (4) autopsy neuropathologic findings (Consortium to Establish a Registry of Alzheimer's Disease [CERAD] NP score, Braak NFT stage, presence of hippocampal sclerosis [HScl] and Lewy bodies [LB], and presence and severity of both arteriolosclerosis and cerebral amyloid angiopathy [CAA; none, mild, moderate, severe]), all of which are associated with antemortem CDR-SOB score within the $\mathrm{AD}$ continuum. ${ }^{30}$ 
Table 1 Characteristics of This NACC Autopsy Cohort

\begin{tabular}{|c|c|c|c|c|}
\hline Characteristic & Total $(n=1,109)$ & $A P O E \varepsilon 2$ & $A P O E \varepsilon 3 / \varepsilon 3$ & APOE $\varepsilon 4$ \\
\hline APOE genotype, $\mathrm{n}(\%)^{\mathrm{a}}$ & NA & $45(4.0)$ & 442 (39.9) & $622(56.1)$ \\
\hline Female, n (\%) & $474(42.7)$ & $22(48.9)$ & $206(46.6)$ & $246(39.5)$ \\
\hline Age at first visit, mean (SD), y & $77.94(9.48)$ & $79.82(10.68)$ & $79.45(9.51)$ & $76.73(9.20)$ \\
\hline Age at death, mean (SD), y & $82.1(9.5)$ & $84.9(11.3)$ & $83.7(9.6)$ & $80.8(9.2)$ \\
\hline Education, mean (SD), $y^{b}$ & $15.3(3.2)$ & $15.6(3.6)$ & $15.3(3.3)$ & $15.2(3.1)$ \\
\hline Visits, median (IQR), n & $3(2-6)$ & $4(3-7)$ & $3.5(2-6)$ & $3(2-6)$ \\
\hline Total length of follow-up from initial visit to death, median (IQR), y & $3.80(1.83-6.09)$ & $5.00(3.10-6.55)$ & $3.80(1.80-6.04)$ & $3.74(1.77-6.05)$ \\
\hline Length of follow-up from initial visit to last clinical visit, median (IQR), y & $2.99(1.03-5.36)$ & $4.45(2.24-5.94)$ & $2.99(1.03-5.38)$ & $2.95(1.02-5.24)$ \\
\hline Length of follow-up from last clinical visit to death, median (IQR), y & $0.68(0.32-1.05)$ & $0.95(0.57-1.39)$ & $0.61(0.29-1.06)$ & $0.68(0.33-1.02)$ \\
\hline \multicolumn{5}{|l|}{ CDR-SOB score, mean (SD) } \\
\hline First visit & $7.5(6.0)$ & $3.8(4.8)$ & $6.9(5.9)$ & $8.2(6.0)$ \\
\hline Final visit & $12.9(5.8)$ & $8.7(6.4)$ & $12.0(6.2)$ & $13.8(5.2)$ \\
\hline \multicolumn{5}{|l|}{ MMSE score, mean (SD) } \\
\hline First visit & $19.2(8.6)$ & $23.3(7.5)$ & $20.0(8.5)$ & $18.3(8.7)$ \\
\hline Final visit & $13.8(9.4)$ & $19.5(8.4)$ & $15.3(9.4)$ & $12.3(9.2)$ \\
\hline \multicolumn{5}{|l|}{ Memory z score, mean (SD) } \\
\hline First visit & $-1.99(1.09)$ & $-1.31(1.36)$ & $-1.82(1.20)$ & $-2.17(0.93)$ \\
\hline Final visit & $-2.19(1.09)$ & $-1.52(1.36)$ & $-2.05(1.20)$ & $-2.39(0.91)$ \\
\hline \multicolumn{5}{|l|}{ Attention z score, mean (SD) } \\
\hline First visit & $-0.76(1.08)$ & $-0.50(1.18)$ & $-0.69(1.05)$ & $-0.84(1.08)$ \\
\hline Final visit & $-1.24(1.25)$ & $-0.82(0.82)$ & $-1.14(1.18)$ & $-1.38(1.33)$ \\
\hline \multicolumn{5}{|l|}{ Executive $z$ score, mean (SD) } \\
\hline First visit & $-1.15(1.44)$ & $-0.63(1.30)$ & $-1.15(1.47)$ & $-1.19(1.42)$ \\
\hline Final visit & $-1.76(1.60)$ & $-1.65(1.71)$ & $-1.82(1.55)$ & $-1.72(1.64)$ \\
\hline \multicolumn{5}{|l|}{ Language $z$ score, mean (SD) } \\
\hline First visit & $-1.69(1.47)$ & $-1.14(1.58)$ & $-1.69(1.48)$ & $-1.74(1.44)$ \\
\hline Final visit & $-2.55(1.59)$ & $-2.03(1.72)$ & $-2.51(1.55)$ & $-2.67(1.59)$ \\
\hline \multicolumn{5}{|l|}{ CERAD NP score, N (\%) } \\
\hline Moderate & $289(26.1)$ & $17(37.8)$ & $152(34.4)$ & $120(26.1)$ \\
\hline Frequent & 820 (73.9) & $28(62.2)$ & $290(65.6)$ & 502 (73.9) \\
\hline \multicolumn{5}{|l|}{ Braak NFT stage, N (\%) } \\
\hline Limbic (III/IV) & $215(19.4)$ & $19(42.2)$ & $111(25.1)$ & $85(13.7)$ \\
\hline Isocortical (V/VI) & $894(80.6)$ & $26(57.8)$ & 331 (74.9) & $537(86.3)$ \\
\hline LB present, N (\%) & $390(35.4)$ & $19(42.2)$ & $137(31.2)$ & $234(37.8)$ \\
\hline HScl, present, n (\%) & $128(11.8)$ & $7(15.6)$ & $47(11.0)$ & $74(12.1)$ \\
\hline \multicolumn{5}{|l|}{ Arteriolosclerosis, n (\%) } \\
\hline None & 165 (17.4) & $6(16.2)$ & 70 (18.9) & $89(16.5)$ \\
\hline Mild & $336(35.4)$ & $11(29.7)$ & $137(36.9)$ & $188(34.8)$ \\
\hline
\end{tabular}


Table 1 Characteristics of This NACC Autopsy Cohort (continued)

\begin{tabular}{|c|c|c|c|c|}
\hline Characteristic & Total $(n=1,109)$ & $A P O E \varepsilon 2$ & APOE $\varepsilon 3 / \varepsilon 3$ & $A P O E \& 4$ \\
\hline Moderate & $325(34.2)$ & $15(40.5)$ & $123(33.2)$ & $187(34.6)$ \\
\hline Severe & $123(13.0)$ & $5(13.5)$ & $41(11.1)$ & 77 (14.2) \\
\hline \multicolumn{5}{|l|}{ CAA, n (\%) } \\
\hline None & $244(22.4)$ & $12(27.3)$ & 147 (33.7) & 85 (13.9) \\
\hline Mild & 342 (31.3) & $10(22.7)$ & $142(32.6)$ & $190(31.1)$ \\
\hline Moderate & $299(27.4)$ & $11(25.0)$ & $90(20.6)$ & 198 (32.4) \\
\hline Severe & 206 (18.9) & $11(25.0)$ & $57(13.1)$ & 138 (22.6) \\
\hline
\end{tabular}

Abbreviations: $\mathrm{CAA}=$ cerebral amyloid angiopathy; $\mathrm{CDR}-\mathrm{SOB}=$ Clinical Dementia Rating scale Sum of Boxes; $\mathrm{CERAD}=$ Consortium to Establish a Registry of Alzheimer's Disease; $\mathrm{HScl}=$ hippocampal sclerosis; IQR = interquartile range; LB = Lewy bodies; MMSE = Mini-Mental State Examination; NA = not applicable; NACC = National Alzheimer's Coordinating Center; NFT = neurofibrillary tangle; NP = neuritic plaque.

aPOE $\varepsilon 2 / \varepsilon 4$ carriers were excluded.

${ }^{\mathrm{b}}$ Not available for 7 individuals.

\section{Statistics}

Statistical analyses were run in $\mathrm{R}$ software version 3.6 using $\mathrm{R}$ package $1 \mathrm{cmm}$ ( $\mathrm{R}$ Foundation for Statistical Computing). ${ }^{31}$ Outcome variables included CDR-SOB score, MMSE score, and cognitive domain-specific scores. For the last ones, the scores of the neuropsychological outcome variables at each visit were converted into $z$ scores. Briefly, tests were grouped in 4 cognitive domains based on a validated factor structure ${ }^{32}$ as follows: $z$ scores for logical memory immediate and delayed recall were averaged into a memory composite score; $z$ scores for Trail Making Tests A and B and Digit-Symbol Substitution Test were averaged into an executive composite score; $z$ scores for digits forward trials and length, and digits backward trials and length were averaged into an attention composite score; and $z$ scores for animals and vegetables in 1 minute and Boston Naming Test were averaged into a language composite score.

To evaluate the association between $A P O E$ genotype and rate of cognitive decline as reflected in longitudinal global functional and cognitive measures (CDR-SOB and MMSE scores), we used statistical methods previously described in detail elsewhere. ${ }^{33}$ Briefly, the main specifications and advantages of this methodology are as follows:

1. Reverse time. Traditional forward time analysis precludes linking the neuropathologic measures with individual cognitive trajectories during life because neuropathologic measures are time varying and measurable only at postmortem examination. Therefore, we treated the neuropathologic variables as baseline covariates and modeled the longitudinal cognitive trajectories in reverse time, that is, beginning with neuropsychological scores at the visit closest to death $(<2$ years prior per inclusion criteria) and moving backward toward the scores obtained at the initial visit.
2. Shared latent classes. Longitudinal cognitive trajectories are truncated by events such as last visit or death, and the neuropathologic variables are ascertained at death. Therefore, any potential association between the longitudinal cognitive trajectories and these time-to-events must be accounted for. To achieve this and to control for any unmeasured (latent) features that may be associated with both, we implemented a joint latent class model for the longitudinal cognitive trajectories (mixed-effects submodel), the time-to-event analyses (death to first NACC visit, Cox proportional hazards submodel), and class membership (logistic submodel) and evaluated the number of latent classes best supported by the data with the Bayesian information criterion (BIC).

3. Change point. Longitudinal neuropsychological testing is often affected by floor or ceiling effects as the dementia advances and individuals become untestable. To account for these possible floor/ceiling effects of cognitive outcomes and to capture any change in the slope of cognitive trajectories in advanced $\mathrm{AD}$, we used a piecewise linear model with 2 different linear slopes before and after a change point and determined the change point best supported by the data (2, 2.5 , or 3 years before death) with the BIC. We decided not to use change point as a random variable due to the complexity of the model.

4. Right truncation adjustment by time to death. Because this is a clinicopathologic autopsy sample, time to last NACC visit is right truncated by time to death. To avoid potential bias derived from the oversampling of shorter times to death, we adjusted for right truncation of time to last visit by time to death. For a more detailed discussion of the statistical methodology, we refer the reader to our previous article. ${ }^{32}$

The covariates used in the mixed-effects submodel for the longitudinal cognitive trajectory analyses and in Cox 


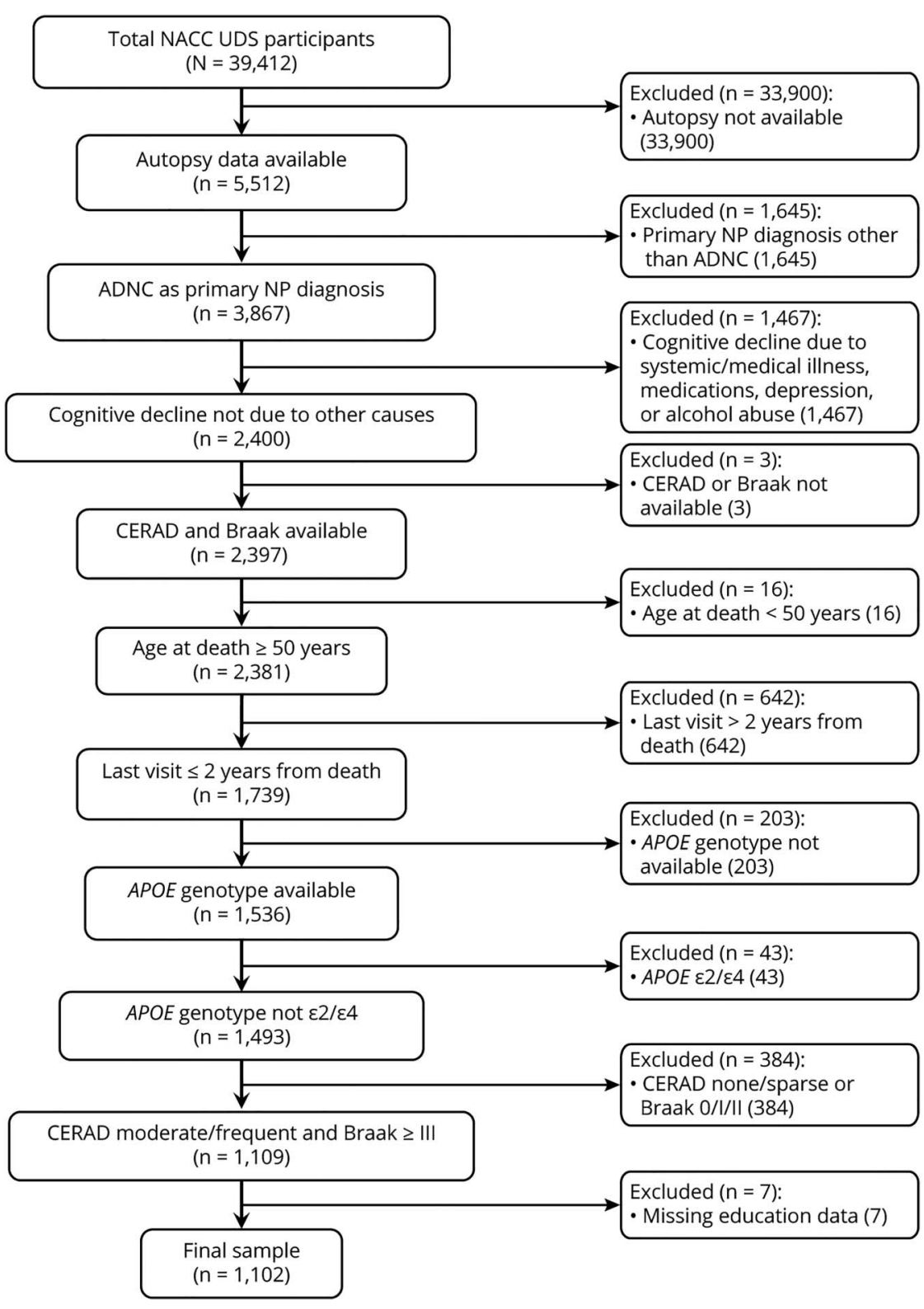

ADNC = Alzheimer disease neuropathological changes; $C E R A D=$ Consortium to Establish a Registry of Alzheimer's Disease; NACC = National Alzheimer's Coordinating Center; NP = neuritic plaque; UDS = Uniform Data Set. proportional hazards submodel for the time-to-event analyses included sex, education, age at death, $A P O E$ genotype (presence vs absence of $\varepsilon 2$ allele, and presence vs absence of $\varepsilon 4$ allele, with e3/e3 carriers as reference group), CERAD NP score (frequent vs moderate), and Braak NFT stages (V/VI vs III/IV). After selection of the most suitable number of latent classes and change point for each cognitive variable, CERAD NP score, Braak NFT stage, and the neuropathologic comorbid pathologies (i.e., presence of $\mathrm{HScl}$ and $\mathrm{LB}$, presence and severity of both arteriolosclerosis and CAA [none, mild, moderate, severe]) with a significant association with the antemortem cognitive variable were added to the models. To assess the differential effects of APOE genotype, CERAD NP score, and Braak NFT stage on cognitive trajectory, we allowed interaction terms between each of these 3 variables and the slope before or after the change point in the modeling. We started with simpler models with $A P O E$ genotype as predictor and each cognitive measure as outcome variable, adjusted by age, sex, education, CERAD NP score, and Braak NFT stage (model 1). To investigate whether APOE genotype effects on the rate of cognitive decline are independent from $\mathrm{ADNC}$ and comorbid pathologies, we then built more complex models by further adjusting for interaction terms between CERAD NP score or Braak NFT stage and the slope before or after the change point and for concurrent pathologies (model 2). To use the autopsy variables in the forwardtime translation of the analyses, we assumed that amyloid plaque burden does not substantially change over the clinical course of $\mathrm{AD}$ and that the sequence of Braak NFT stages is preserved over the extent of longitudinal follow-up. These 
Table 2 Associations of APOE Alleles With Neuropathologic Findings at Autopsy

\begin{tabular}{|c|c|c|c|c|c|c|c|c|}
\hline & \multicolumn{8}{|c|}{ Neuropathologic outcome measure } \\
\hline & \multirow[b]{2}{*}{$\begin{array}{l}\text { Braak NFT } \\
\text { stage (V/VI } \\
\text { vs III/IV) }\end{array}$} & \multirow{2}{*}{$\begin{array}{l}\text { CERAD NP } \\
\text { score } \\
\text { (frequent vs } \\
\text { moderate) }\end{array}$} & \multicolumn{3}{|l|}{ CAA } & \multirow[b]{2}{*}{$\begin{array}{l}\text { LB (present } \\
\text { vs none) }\end{array}$} & \multirow[b]{2}{*}{$\begin{array}{l}\text { HScl (present } \\
\text { vs none) }\end{array}$} & \multirow{2}{*}{$\begin{array}{l}\text { Arteriolosclerosis } \\
\text { (mild vs none, } \\
\text { moderate vs } \\
\text { mild, or severe } \\
\text { vs moderate) }\end{array}$} \\
\hline & & & Mild vs none & $\begin{array}{l}\text { Moderate vs } \\
\text { mild }\end{array}$ & $\begin{array}{l}\text { Severe vs } \\
\text { moderate }\end{array}$ & & & \\
\hline & $\begin{array}{l}\log \text { OR } \\
(95 \% \mathrm{Cl})\end{array}$ & $\begin{array}{l}\log \text { OR } \\
(95 \% \mathrm{Cl})\end{array}$ & $\begin{array}{l}\text { Log OR } \\
(95 \% \mathrm{Cl})\end{array}$ & $\begin{array}{l}\text { Log OR } \\
(95 \% \mathrm{Cl})\end{array}$ & $\begin{array}{l}\text { Log OR } \\
(95 \% \mathrm{CI})\end{array}$ & $\begin{array}{l}\text { Log OR } \\
(95 \% \mathrm{CI}]\end{array}$ & $\begin{array}{l}\text { Log OR } \\
(95 \% \mathrm{Cl})\end{array}$ & $\begin{array}{l}\log \text { OR } \\
(95 \% \mathrm{Cl})\end{array}$ \\
\hline $\begin{array}{l}\text { Presence } \\
\text { of } A P O E \& 2 \\
\text { allele }\end{array}$ & $\begin{array}{l}-0.19 \\
(-0.29 \text { to }-0.08)\end{array}$ & $\begin{array}{l}-0.10 \\
(-0.22 \text { to } 0.03)\end{array}$ & $\begin{array}{l}0.06 \\
(-0.24 \text { to } 0.36)\end{array}$ & $\begin{array}{l}0.06 \\
(-0.24 \text { to } 0.36)\end{array}$ & $\begin{array}{l}0.06 \\
(-0.24 \text { to } 0.36)\end{array}$ & $\begin{array}{l}0.07 \\
(-0.08 \text { to } 0.21)\end{array}$ & $\begin{array}{l}0.03 \\
(-0.07 \text { to } 0.13)\end{array}$ & $\begin{array}{l}0.03 \\
(-0.34 \text { to } 0.39)\end{array}$ \\
\hline $\begin{array}{l}\text { Presence } \\
\text { of } A P O E \& 4 \\
\text { allele }\end{array}$ & $\begin{array}{l}0.06 \\
\text { (0.02 to } 0.11)\end{array}$ & $\begin{array}{l}0.12 \\
\text { (0.07 to } 0.17)\end{array}$ & $\begin{array}{l}0.80 \\
(0.46 \text { to } 1.14)\end{array}$ & $\begin{array}{l}0.48 \\
(0.15 \text { to } 0.81)\end{array}$ & $\begin{array}{l}-0.01 \\
(-0.40 \text { to } 0.37)\end{array}$ & $\begin{array}{l}0.05 \\
(-0.01 \text { to } 0.11)\end{array}$ & $\begin{array}{l}0.02 \\
(-0.02 \text { to } 0.06)\end{array}$ & $\begin{array}{l}0.16 \\
(0.01 \text { to } 0.30)\end{array}$ \\
\hline $\begin{array}{l}\text { Presence } \\
\text { of } 1 A P O E \\
\varepsilon 4 \text { allele }\end{array}$ & $\begin{array}{l}0.05 \\
(0.01 \text { to } 0.10)\end{array}$ & $\begin{array}{l}0.13 \\
(0.07 \text { to } 0.18)\end{array}$ & $\begin{array}{l}0.90 \\
\text { (0.55 to } 1.26)\end{array}$ & $\begin{array}{l}0.25 \\
(-0.07 \text { to } 0.57)\end{array}$ & $\begin{array}{l}-0.18 \\
(-0.55 \text { to } 0.21)\end{array}$ & $\begin{array}{l}0.04 \\
(-0.02 \text { to } 0.10)\end{array}$ & $\begin{array}{l}0.02 \\
(-0.02 \text { to } 0.06)\end{array}$ & $\begin{array}{l}0.14 \\
(-0.02 \text { to } 0.29)\end{array}$ \\
\hline $\begin{array}{l}\text { Presence } \\
\text { of } 2 A P O E \\
\varepsilon 4 \text { alleles }\end{array}$ & $\begin{array}{l}0.10 \\
(0.03 \text { to } 0.17)\end{array}$ & $\begin{array}{l}0.11 \\
(0.03 \text { to } 0.18)\end{array}$ & $\begin{array}{l}0.75 \\
\text { (0.56 to } 0.95)\end{array}$ & $\begin{array}{l}0.75 \\
\text { ( } 0.56 \text { to } 0.95)\end{array}$ & $\begin{array}{l}0.75 \\
(0.56 \text { to } 0.95)\end{array}$ & $\begin{array}{l}0.07 \\
(-0.02 \text { to } 0.16)\end{array}$ & $\begin{array}{l}0.01 \\
(-0.05 \text { to } 0.07)\end{array}$ & $\begin{array}{l}0.22 \\
(0.002 \text { to } 0.44)\end{array}$ \\
\hline
\end{tabular}

Abbreviations: $\mathrm{CAA}=$ cerebral amyloid angiopathy; CERAD = Consortium to Establish a Registry of Alzheimer's Disease; $\mathrm{Cl}=$ confidence interval; $\mathrm{HSCl}=$ hippocampal sclerosis; LB = Lewy bodies; NFT = neurofibrillary tangle; NP = neuritic plaque; OR = odds ratio.

All analyses were adjusted by age at death, sex, and education. Braak NFT stage and CAA analyses were also adjusted by CERAD NP score. Numbers of individuals with $A P O E \& 2, A P O E \varepsilon 3 / \mathrm{e} 3$, and $A P O E \& 4$ used are 44,440 , and 618 , respectively. Numbers of individuals with 1 and 2 APOE $\varepsilon 4$ alleles are 468 and 150 , respectively.

assumptions are well supported by prior $\beta$-amyloid $(A \beta)$ and tau PET imaging studies. ${ }^{34,35}$

\section{Data Availability}

The NACC database is a public resource available to researchers. Data requests can be submitted online at the following NACC website: alz.washington.edu/NONMEMBER/QUERY/datareqnew.html.

\section{Results}

\section{Characteristics of Study Participants}

Table 1 summarizes the demographic characteristics, neuropathologic autopsy findings, and cognitive measures of the study participants at baseline and last clinical visit. The flowchart in figure 1 shows that 1,109 individuals met the inclusion criteria and none of the exclusion criteria, but 7 individuals had to be excluded due to missing education data, hence the final sample of 1,102 .

\section{Selection of Neuropathologic Covariates for Longitudinal Modeling}

To select the neuropathologic covariates for the longitudinal models, we first investigated the effects of $A P O E$ alleles on $\mathrm{ADNC}$ and comorbid pathologies in this convenience sample using multivariate regression models controlling for age at death, sex, and education (table 2). The APOE $\varepsilon 4$ allele was associated with a higher CERAD NP score (frequent vs moderate), a higher Braak stage (V/VI vs III/IV), more severe CAA (moderate vs mild and mild vs none), and more severe arteriolosclerosis than the APOE $\varepsilon 3 / \varepsilon 3$ reference group. An $A P O E \& 4$ dose-dependent effect was observed for most of these associations. In contrast, the APOE $\varepsilon 2$ allele was associated with a lower Braak stage (III/IV vs V/VI) compared to the APOE $\varepsilon 3 / \varepsilon 3$ group but not with a lower CERAD NP score (log odds ratio $-0.10,95 \%$ confidence interval [CI] -0.22 to $0.03, p=0.141$ ). No significant effect was observed for either APOE allele on the presence of LB or HScl. These results largely agree with those from a NACC sample of cognitively impaired (CDR-SOB score $>0$ ) selected to represent the $\mathrm{AD}$ clinicopathologic continuum. ${ }^{5}$

To further refine the selection of neuropathologic covariates, we examined the effects of concurrent pathologies (CAA, LB, $\mathrm{HScl}$, and arteriolosclerosis) on antemortem global cognitive measures (CDR-SOB and MMSE scores) and domainspecific composites. With age at death, sex, education, CERAD NP score, Braak NFT stage, and APOE genotype held constant, presence vs absence of $\mathrm{HScl}$ was associated with worse memory $(-0.294 \pm 0.063, p<0.001)$ and language $(-0.666 \pm 0.149, p<0.001)$, higher CDR-SOB $(2.694 \pm$ $0.436, p<0.001)$ and lower MMSE $(-3.801 \pm 0.752, p<$ 0.001 ) scores, presence vs absence of LB with worse executive function $(-0.286 \pm 0.118, p=0.015)$, severe arteriolosclerosis vs none with worse attention $(-0.376 \pm 0.140, p=0.007)$, and moderate and severe CAA vs none with higher CDR-SOB (moderate vs none $1.400 \pm 0.410, p<0.001$; severe vs none $0.977 \pm 0.453, p=0.031$ ) and lower MMSE (moderate vs none $-2.478 \pm 0.700, p=0.002$; severe vs none $-1.665 \pm$ $0.792, p=0.035)$ scores. 
Table 3 Effects of APOE Alleles on Cognitive Trajectories in Forward Time Scale >3 Years From Death

\begin{tabular}{|c|c|c|c|c|c|c|c|}
\hline \multirow{2}{*}{$\begin{array}{l}\text { Outcome } \\
\text { contrast }\end{array}$} & \multirow[b]{2}{*}{ No. } & \multicolumn{3}{|l|}{ Model 1} & \multicolumn{3}{|l|}{ Model 2} \\
\hline & & Estimate & SE & $95 \% \mathrm{Cl}$ & Estimate & SE & $95 \% \mathrm{Cl}$ \\
\hline CDR-SOB score & 1,102 & & & & & & \\
\hline CERAD NP FREQ vs MOD & & NA & NA & NA & 0.185 & 0.072 & 0.044 to 0.326 \\
\hline Braak NFT V/VI vs III/IV & & NA & NA & NA & 0.308 & 0.078 & 0.154 to 0.461 \\
\hline \multicolumn{8}{|l|}{ APOE genotype } \\
\hline$\varepsilon 2$ vs $\varepsilon 3 / \varepsilon 3$ & & 0.214 & 0.141 & -0.063 to 0.492 & 0.204 & 0.130 & -0.050 to 0.458 \\
\hline$\varepsilon 4$ vs $\varepsilon 3 / \varepsilon 3$ & & 0.686 & 0.082 & 0.525 to 0.846 & 0.660 & 0.073 & 0.517 to 0.803 \\
\hline$\varepsilon 2$ vs $\varepsilon 4$ & & -0.471 & 0.129 & -0.724 to -0.218 & -0.456 & 0.136 & -0.724 to -0.189 \\
\hline MMSE score & 988 & & & & & & \\
\hline CERAD NP FREQ Vs MOD & & NA & NA & NA & -0.402 & 0.101 & -0.600 to -0.205 \\
\hline Braak NFT V/VI vs III/IV & & NA & NA & NA & -0.234 & 0.113 & -0.457 to -0.012 \\
\hline \multicolumn{8}{|l|}{ APOE genotype } \\
\hline$\varepsilon 2$ vs $\varepsilon 3 / \varepsilon 3$ & & 0.596 & 0.194 & 0.215 to 0.977 & 0.383 & 0.197 & -0.003 to 0.769 \\
\hline$\varepsilon 4$ vs $\varepsilon 3 / \varepsilon 3$ & & -0.427 & 0.098 & -0.619 to -0.235 & -0.475 & 0.107 & -0.684 to -0.266 \\
\hline$\varepsilon 2$ vs $\varepsilon 4$ & & 1.023 & 0.195 & 0.640 to 1.405 & 0.858 & 0.207 & 0.453 to 1.263 \\
\hline Memory & 814 & & & & & & \\
\hline CERAD NP FREQ vs MOD & & NA & NA & NA & -0.027 & 0.015 & -0.056 to 0.003 \\
\hline Braak NFT V/VI vs III/IV & & NA & NA & NA & -0.081 & 0.017 & -0.114 to -0.047 \\
\hline \multicolumn{8}{|l|}{ APOE genotype } \\
\hline$\varepsilon 2$ vs $\varepsilon 3 / \varepsilon 3$ & & 0.033 & 0.031 & -0.027 to 0.093 & 0.013 & 0.031 & -0.047 to 0.073 \\
\hline$\varepsilon 4$ vs $\varepsilon 3 / \varepsilon 3$ & & -0.055 & 0.014 & -0.083 to -0.027 & -0.042 & 0.014 & -0.070 to -0.014 \\
\hline$\varepsilon 2$ vs $\varepsilon 4$ & & 0.088 & 0.031 & 0.027 to 0.148 & 0.055 & 0.031 & -0.006 to 0.117 \\
\hline Attention & 826 & & & & & & \\
\hline CERAD NP FREQ vs MOD & & NA & NA & NA & -0.026 & 0.020 & -0.065 to 0.013 \\
\hline Braak NFT V/VI vs III/IV & & NA & NA & NA & -0.079 & 0.024 & -0.125 to -0.032 \\
\hline \multicolumn{8}{|l|}{ APOE genotype } \\
\hline$\varepsilon 2$ vs $\varepsilon 3 / \varepsilon 3$ & & -0.010 & 0.035 & -0.079 to 0.058 & 0.008 & 0.049 & -0.088 to 0.104 \\
\hline$\varepsilon 4$ vs $\varepsilon 3 / \varepsilon 3$ & & -0.059 & 0.019 & -0.097 to -0.022 & -0.034 & 0.019 & -0.070 to 0.002 \\
\hline$\varepsilon 2$ vs $\varepsilon 4$ & & 0.049 & 0.036 & -0.022 to 0.120 & 0.042 & 0.049 & -0.055 to 0.138 \\
\hline Executive & 611 & & & & & & \\
\hline CERAD NP FREQ VS MOD & & NA & NA & NA & -0.097 & 0.025 & -0.146 to -0.049 \\
\hline Braak NFT V/VI vs III/IV & & NA & NA & NA & -0.081 & 0.026 & -0.132 to -0.030 \\
\hline \multicolumn{8}{|l|}{ APOE genotype } \\
\hline$\varepsilon 2$ vs $\varepsilon 3 / \varepsilon 3$ & & -0.001 & 0.048 & -0.095 to 0.093 & 0.099 & 0.045 & 0.010 to 0.187 \\
\hline$\varepsilon 4$ vs $\varepsilon 3 / \varepsilon 3$ & & -0.064 & 0.026 & -0.115 to -0.014 & -0.063 & 0.025 & -0.112 to -0.014 \\
\hline$\varepsilon 2$ vs $\varepsilon 4$ & & 0.063 & 0.048 & -0.031 to 0.158 & 0.162 & 0.047 & 0.069 to 0.254 \\
\hline Language & 826 & & & & & & \\
\hline CERAD NP FREQ vs MOD & & NA & NA & NA & -0.051 & 0.018 & -0.086 to -0.016 \\
\hline
\end{tabular}


Table 3 Effects of APOE Alleles on Cognitive Trajectories in Forward Time Scale >3 Years From Death (continued)

\begin{tabular}{|c|c|c|c|c|c|c|c|}
\hline \multirow{2}{*}{$\begin{array}{l}\text { Outcome } \\
\text { contrast }\end{array}$} & \multirow[b]{2}{*}{ No. } & \multicolumn{3}{|l|}{ Model 1} & \multicolumn{3}{|l|}{ Model 2} \\
\hline & & Estimate & SE & $95 \% \mathrm{Cl}$ & Estimate & SE & $95 \% \mathrm{Cl}$ \\
\hline Braak NFT V/VI vs III/IV & & NA & NA & NA & -0.112 & 0.019 & -0.151 to -0.074 \\
\hline \multicolumn{8}{|l|}{ APOE genotype } \\
\hline$\varepsilon 2$ vs $\varepsilon 3 / \varepsilon 3$ & & 0.119 & 0.039 & 0.043 to 0.194 & 0.210 & 0.037 & 0.137 to 0.283 \\
\hline$\varepsilon 4$ vs $\varepsilon 3 / \varepsilon 3$ & & -0.053 & 0.021 & -0.094 to -0.011 & -0.034 & 0.018 & -0.069 to 0.001 \\
\hline$\varepsilon 2$ vs $\varepsilon 4$ & & 0.171 & 0.037 & 0.099 to 0.243 & 0.245 & 0.038 & 0.170 to 0.319 \\
\hline
\end{tabular}

Abbreviations: $C E R A D=$ Consortium to Establish a Registry of Alzheimer's Disease; $\mathrm{Cl}$ = confidence interval; $\mathrm{FREQ}=$ frequent; $\mathrm{MOD}=\mathrm{moderate} ; \mathrm{NA}=$ not applicable; NFT = neurofibrillary tangle; NP = neuritic plaque.

Estimates represent the unstandardized effect sizes (i.e., differences in trajectory slopes for each cognitive outcome and for each $A P O E$ genotype contrast). Model 1 is adjusted by age at death, sex, education, and Alzheimer disease neuropathological changes (CERAD NP score FREQ vs MOD and Braak NFT stage VI VI vs III/IV). Model 2 is further adjusted by the interactions between Alzheimer disease neuropathological changes and the slope of cognitive trajectories and by concurrent pathologies.

\section{Longitudinal Modeling Reveals Opposing Effects of APOE Alleles on Global Cognitive Trajectory}

Overall, on the basis of the BIC, longitudinal models with a change point at 3 years before death were preferred to those with a 2- or 2.5-year change point; with a change point at 3 years, the 2-latent-class model was preferred over the 1-latentclass model for all the cognitive outcomes.

Table 3 shows the results of these models controlled for age at death, sex, education, and ADNC severity (model 1) and with additional adjustments for the effect of ADNC on rate of cognitive decline and for presence and severity of concurrent pathologies (model 2) $>3$ years before death. Figure 2 illustrates these results. With only demographic and ADNC variables (model 1) held constant, $A P O E \& 4$ carriers exhibited $\approx 1.5$ times faster progression by CDR-SOB score than APOE $\varepsilon 3 / \varepsilon 3$ carriers ( 2.12 vs 1.44 points per year, $95 \% \mathrm{CI}$ for the difference $0.53-0.85)$ and $\approx 1.3$ times faster than APOE $\varepsilon 2$ carriers $(2.12$ vs 1.65 points per year, $95 \%$ CI $0.22-0.72$ ), but $A P O E \varepsilon 2$ carriers did not significantly differ from $A P O E \varepsilon 3 / \varepsilon 3$ carriers ( 1.65 vs 1.44 points per year, $95 \% \mathrm{CI}-0.06$ to 0.49 ) (figure 2, A and B). By MMSE score, APOE $\varepsilon 4$ carriers had $\approx 1.1$ times faster decline than $A P O E \varepsilon 3 / \varepsilon 3$ carriers $(-3.45$ vs -3.03 points per year, $95 \% \mathrm{CI}-0.62$ to -0.24$)$ and $\approx 1.4$ times faster decline than APOE $\varepsilon 2$ carriers ( -3.45 vs -2.43 points per year, $95 \% \mathrm{CI}$ -1.41 to -0.64$)$, whereas $A P O E \& 2$ carriers had $\approx 1.2$ times slower decline than $A P O E \quad \varepsilon 3 / \varepsilon 3$ carriers $(-2.43$ vs -3.03 points per year, 95\% CI 0.22-0.98) (figure 2, E and F).

Holding all demographic, ADNC, and comorbid neuropathologic covariates constant and controlling for the effect of ADNC on the slope of cognitive decline (model 2), we found that $A P O E$ $\varepsilon 4$ carriers exhibited $\approx 1.6$ times faster clinical progression by CDR-SOB score than APOE $\varepsilon 3 / \varepsilon 3$ carriers ( 1.80 vs 1.14 points per year, $95 \% \mathrm{CI}$ for the difference $0.52-0.80)$ and $\approx 1.3$ times faster clinical progression than $A P O E \& 2$ carriers ( 1.80 vs 1.34 points per year, 95\% CI 0.19-0.72). In contrast, APOE $\varepsilon 2$ carriers did not significantly differ from $A P O E \varepsilon 3 / \varepsilon 3$ carriers (1.34 vs 1.14 points per year, $95 \% \mathrm{CI}-0.05$ to 0.46 ) (figure 2, C and $\mathrm{D})$. By MMSE score, $A P O E \varepsilon 4$ carriers had $\approx 1.2$ times faster decline than $A P O E \varepsilon 3 / \varepsilon 3$ carriers $(-2.90$ vs -2.43 points per year, $95 \% \mathrm{CI}-0.68$ to -0.27$)$ and $\approx 1.4$ times faster decline than APOE $\varepsilon 2$ carriers $(-2.90$ vs -2.04 points per year, $95 \% \mathrm{CI}-1.26$ to -0.45$)$, whereas $A P O E \& 2$ carriers had $\approx 1.2$ times slower decline than $A P O E \varepsilon 3 / \varepsilon 3$ carriers $(-2.04$ vs -2.43 points per year, 95\% CI 0.00-0.77) (figure 2, G and H).

As expected, the 3-year change point revealed and isolated ceiling effects of CDR-SOB score and floor effects of MMSE score within 3 years before death (table 4 and figure 2). In this time frame, the $A P O E \varepsilon 2$ carriers exhibited a significantly slower increase in CDR-SOB score compared to the APOE $\varepsilon 3 / \varepsilon 3$ group ( 1.70 vs 2.28 points per year, $95 \% \mathrm{CI}-1.07$ to -0.08 ), but a ceiling effect of the CDR-SOB score in the APOE $\varepsilon 4$ group is apparent, with a slower decline relative to the APOE $\varepsilon 3 / \varepsilon 3$ group ( 2.02 vs 2.28 points per year, $95 \% \mathrm{CI}-0.06$ to -0.45 ). Indeed, $29 \% A P O E \varepsilon 4$ carriers had already reached the maximum CDR-SOB score of 18 at the 3-year change time point compared to $19 \%$ of $A P O E \varepsilon 3 / \varepsilon 3$ carriers. Similarly, the APOE $\varepsilon 4$ carriers showed a significantly faster decline in MMSE score than the $A P O E \varepsilon 3 / \varepsilon 3$ group $(-3.37$ vs -2.97 points per year, $95 \% \mathrm{CI}[-0.79$ to -0.01$)$, but a floor effect of the MMSE score became apparent in the $A P O E \varepsilon 3 / \varepsilon 3$ group, causing $A P O E \varepsilon 2$ carriers to show a nonsignificant trend toward an apparent faster decline ( -3.54 vs -2.97 points per year, $95 \% \mathrm{CI}-1.47$ to 0.34$)$. As an example, $8.2 \%$ of $A P O E \varepsilon 3 / \varepsilon 3$ carriers had reached an MMSE score $\leq 3$ at the 3-year change time point vs none of the APOE $\varepsilon 2$ carriers.

\section{Longitudinal Modeling Reveals Opposing Effects of APOE Alleles on Specific Cognitive Domains}

Without controlling for the effect of ADNC on rate of cognitive decline or for concurrent pathologies, $A P O E \& 4$ carriers had a significantly faster decline in all 4 domains analyzed 
A

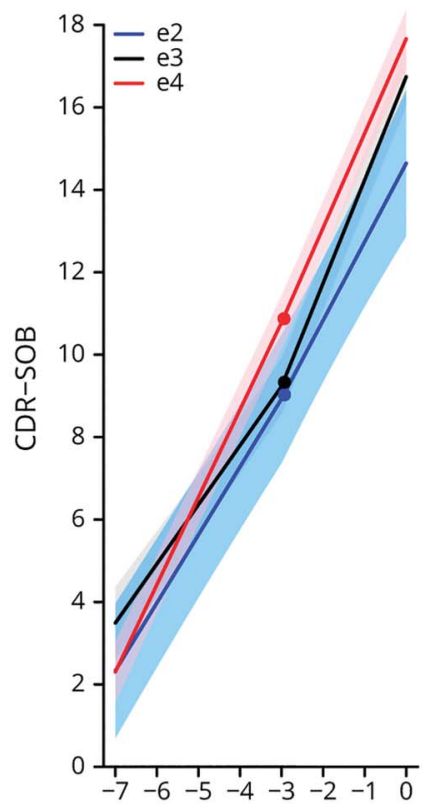

E

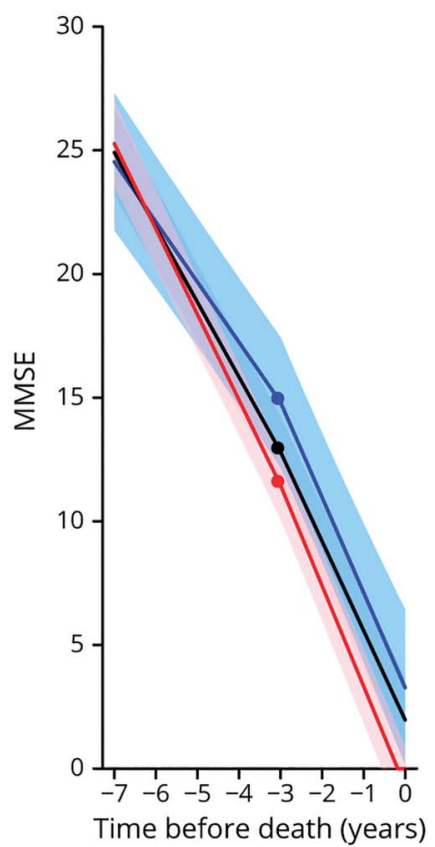

B

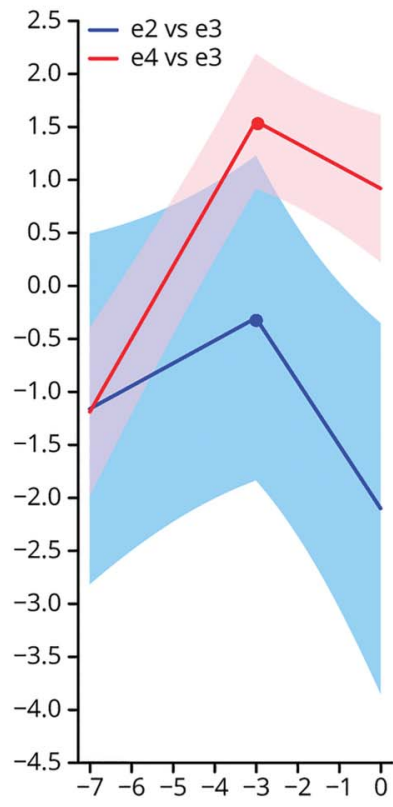

F

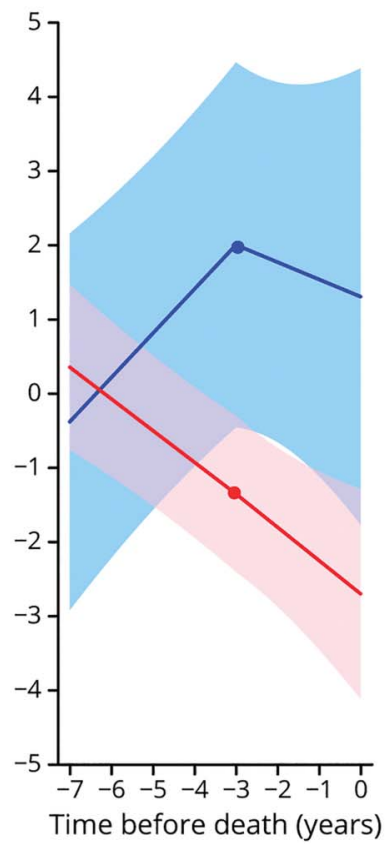

C

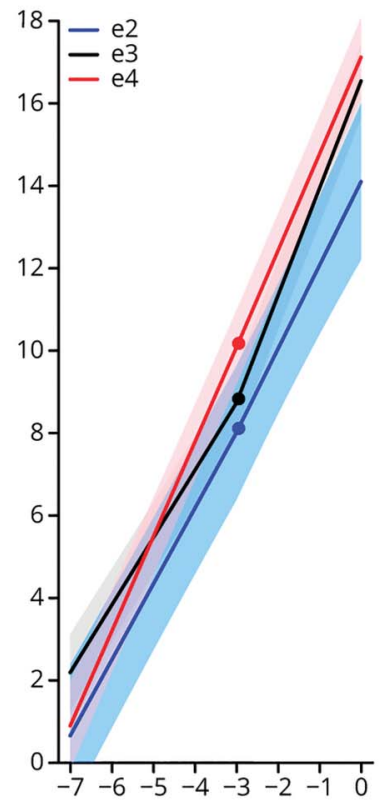

G

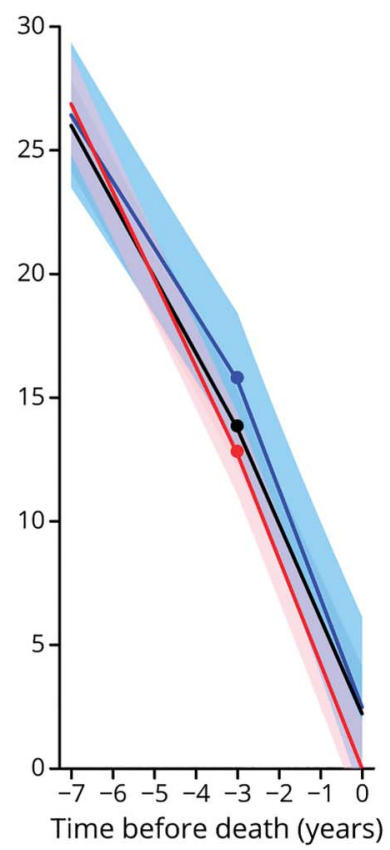

D

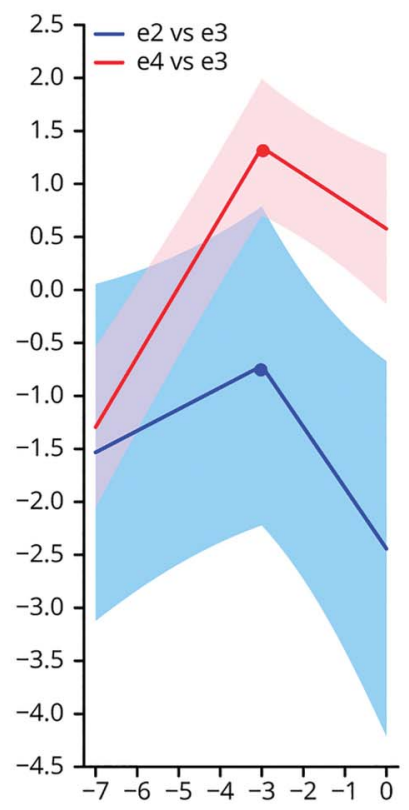

$\mathrm{H}$

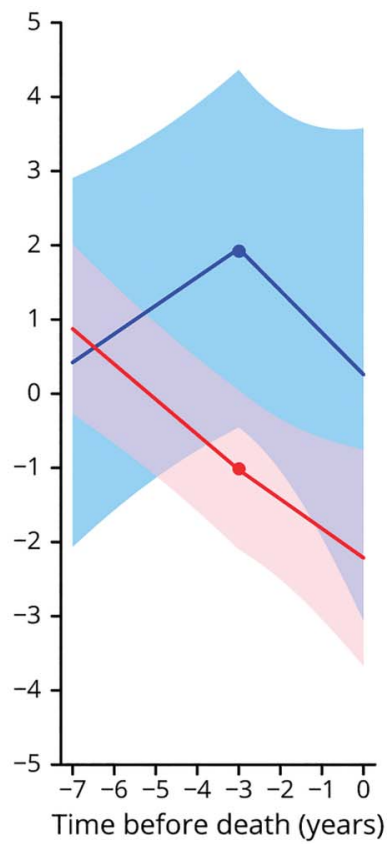

(A and E) Model-based cognitive trajectories of Clinical Dementia Rating Sum of Boxes (CDR-SOB) (A) and Mini-Mental State Examination MMSE (E) Scores by $A P O E$ allele groups ( $A P O E \varepsilon 3 / \varepsilon 3, A P O E \varepsilon 2$, and $A P O E \varepsilon 4$ carriers) with the intercept at the time of death calculated for an 82 -year-old woman with 15 years of education and autopsy findings of frequent Consortium to Establish a Registry of Alzheimer's Disease (CERAD) neuritic plaque (NP) score and Braak neurofibrillary tangle (NFT) stage V/VI, but without adjustments for the effect of these neuropathologic variables on the rate of cognitive decline or for comorbid pathologies (model 1). (C and G) Model-based cognitive trajectories of CDR-SOB (C) and MMSE (G) Scores by APOE group with the intercept at the time of death calculated for an 82-year-old woman with 15 years of education and autopsy findings of frequent CERAD NP score and Braak NFT stage V/VI and no comorbid pathologies and with adjustments for the effect of AD neuropathologic variables (CERAD and Braak) on the rate of cognitive decline and for comorbid pathologies (model 2). Note the nearly identical trajectories with and without controlling for neuropathology. (B, D, F, and $H$ ) Difference of modelbased cognitive trajectories of CDR-SOB (B and D) and MMSE (F and H) scores between APOE allele groups (APOE \&2 and APOE \&4 vs APOE \&3/\&3 carriers) under models 1 ( $B$ and $F$ ) and 2 ( $D$ and $H$ ). Shaded areas represent the corresponding 95\% confidence intervals.

(memory, executive, attention, language) compared to $A P O E$ $\varepsilon 3 / \varepsilon 3$ carriers, whereas $A P O E \varepsilon 2$ carriers had a significantly slower decline in language compared to $A P O E \& 3 / \varepsilon 3$ carriers and in both memory and language compared to APOE \&4 carriers (table 3, figure 3, and figure e-1 available from Dryad: doi.org/10.5061/dryad.w0vt4b8qk). The models controlling 
Table 4 Floor and Ceiling Effects of APOE Alleles on Cognitive Trajectories in Forward Time Scale Within 3 Years From Death

\begin{tabular}{|c|c|c|c|c|c|c|c|}
\hline \multirow{2}{*}{$\begin{array}{l}\text { Outcome } \\
\text { contrast }\end{array}$} & \multirow[b]{2}{*}{ No. } & \multicolumn{3}{|l|}{ Model 1} & \multicolumn{3}{|l|}{ Model 2} \\
\hline & & Estimate & SE & $95 \% \mathrm{Cl}$ & Estimate & SE & $95 \% \mathrm{Cl}$ \\
\hline CDR-SOB score & 1,102 & & & & & & \\
\hline CERAD NP FREQ vs MOD & & NA & NA & NA & 0.081 & 0.117 & -0.149 to 0.311 \\
\hline Braak NFT V/VI vs III/IV & & NA & NA & NA & 0.246 & 0.138 & -0.024 to 0.517 \\
\hline \multicolumn{8}{|l|}{ APOE genotype } \\
\hline$\varepsilon 2$ vs $\varepsilon 3 / \varepsilon 3$ & & -0.599 & 0.246 & -1.082 to -0.116 & -0.575 & 0.252 & -1.070 to -0.080 \\
\hline$\varepsilon 4$ vs $\varepsilon 3 / \varepsilon 3$ & & -0.212 & 0.098 & -0.403 to -0.020 & -0.256 & 0.099 & -0.451 to -0.062 \\
\hline$\varepsilon 2$ vs $\varepsilon 4$ & & -0.388 & 0.244 & -0.866 to 0.091 & -0.319 & 0.251 & -0.811 to 0.173 \\
\hline MMSE score & 988 & & & & & & \\
\hline CERAD NP FREQ vs MOD & & NA & NA & NA & -0.450 & 0.219 & -0.878 to -0.021 \\
\hline Braak NFT V/VI vs III/IV & & NA & NA & NA & -0.417 & 0.242 & -0.892 to 0.058 \\
\hline \multicolumn{8}{|l|}{ APOE genotype } \\
\hline$\varepsilon 2$ vs $\varepsilon 3 / \varepsilon 3$ & & -0.233 & 0.411 & -1.039 to 0.574 & -0.565 & 0.463 & -1.472 to 0.341 \\
\hline$\varepsilon 4$ vs $\varepsilon 3 / \varepsilon 3$ & & -0.449 & 0.184 & -0.810 to -0.088 & -0.396 & 0.201 & -0.789 to -0.002 \\
\hline$\varepsilon 2$ vs $\varepsilon 4$ & & 0.216 & 0.408 & -0.583 to 1.016 & -0.170 & 0.466 & -1.083 to 0.743 \\
\hline Memory & 814 & & & & & & \\
\hline CERAD NP FREQ vs MOD & & NA & NA & NA & 0.019 & 0.034 & -0.047 to 0.086 \\
\hline Braak NFT V/VI vs III/IV & & NA & NA & NA & 0.013 & 0.036 & -0.058 to 0.084 \\
\hline \multicolumn{8}{|l|}{ APOE genotype } \\
\hline$\varepsilon 2$ vs $\varepsilon 3 / \varepsilon 3$ & & -0.279 & 0.073 & -0.421 to -0.137 & -0.255 & 0.073 & -0.398 to -0.111 \\
\hline$\varepsilon 4$ vs $\varepsilon 3 / \varepsilon 3$ & & 0.064 & 0.031 & 0.004 to 0.124 & 0.060 & 0.031 & -0.001 to 0.120 \\
\hline$\varepsilon 2$ vs $\varepsilon 4$ & & -0.343 & 0.072 & -0.485 to -0.202 & -0.314 & 0.073 & -0.458 to -0.171 \\
\hline Attention & 826 & & & & & & \\
\hline CERAD NP FREQ vs MOD & & NA & NA & NA & -0.104 & 0.045 & -0.191 to -0.016 \\
\hline Braak NFT V/VI vs III/IV & & NA & NA & NA & -0.029 & 0.048 & -0.123 to 0.064 \\
\hline \multicolumn{8}{|l|}{ APOE genotype } \\
\hline$\varepsilon 2$ vs $\varepsilon 3 / \varepsilon 3$ & & 0.049 & 0.076 & -0.100 to 0.198 & 0.003 & 0.090 & -0.173 to 0.179 \\
\hline$\varepsilon 4$ vs $\varepsilon 3 / \varepsilon 3$ & & 0.012 & 0.036 & -0.059 to 0.083 & 0.028 & 0.074 & -0.118 to 0.174 \\
\hline$\varepsilon 2$ vs $\varepsilon 4$ & & 0.037 & 0.076 & -0.112 to 0.187 & -0.025 & 0.099 & -0.219 to 0.169 \\
\hline Executive & 611 & & & & & & \\
\hline CERAD NP FREQ vs MOD & & NA & NA & NA & 0.060 & 0.061 & -0.060 to 0.179 \\
\hline Braak NFT V/VI vs III/IV & & NA & NA & NA & -0.142 & 0.062 & -0.263 to -0.020 \\
\hline \multicolumn{8}{|l|}{ APOE genotype } \\
\hline$\varepsilon 2$ vs $\varepsilon 3 / \varepsilon 3$ & & 0.018 & 0.111 & -0.201 to 0.236 & 0.051 & 0.117 & -0.179 to 0.281 \\
\hline$\varepsilon 4$ vs $\varepsilon 3 / \varepsilon 3$ & & 0.029 & 0.061 & -0.090 to 0.149 & 0.057 & 0.064 & -0.069 to 0.182 \\
\hline$\varepsilon 2$ vs $\varepsilon 4$ & & -0.012 & 0.112 & -0.232 to 0.208 & -0.005 & 0.116 & -0.232 to 0.221 \\
\hline Language & 826 & & & & & & \\
\hline
\end{tabular}


Table 4 Floor and Ceiling Effects of APOE Alleles on Cognitive Trajectories in Forward Time Scale Within 3 Years From Death (continued)

\begin{tabular}{|c|c|c|c|c|c|c|c|}
\hline \multirow{2}{*}{$\begin{array}{l}\text { Outcome } \\
\text { contrast }\end{array}$} & \multirow[b]{2}{*}{ No. } & \multicolumn{3}{|l|}{ Model 1} & \multicolumn{3}{|l|}{ Model 2} \\
\hline & & Estimate & SE & $95 \% \mathrm{Cl}$ & Estimate & SE & $95 \% \mathrm{Cl}$ \\
\hline CERAD NP FREQ vs MOD & & NA & NA & NA & -0.123 & 0.041 & -0.204 to -0.042 \\
\hline Braak NFT V/VI vs III/IV & & NA & NA & NA & -0.128 & 0.043 & -0.213 to 0.043 \\
\hline \multicolumn{8}{|l|}{ APOE genotype } \\
\hline$\varepsilon 2$ vs $\varepsilon 3 / \varepsilon 3$ & & 0.089 & 0.081 & -0.069 to 0.248 & 0.124 & 0.080 & -0.032 to 0.280 \\
\hline$\varepsilon 4$ vs $\varepsilon 3 / \varepsilon 3$ & & -0.068 & 0.039 & -0.145 to 0.009 & 0.013 & 0.040 & -0.066 to 0.091 \\
\hline$\varepsilon 2$ vs $\varepsilon 4$ & & 0.157 & 0.080 & 0.001 to 0.313 & 0.111 & 0.080 & -0.045 to 0.267 \\
\hline
\end{tabular}

Abbreviations: $\mathrm{CDR}-\mathrm{SOB}=$ Clinical Dementia Rating scale Sum of Boxes; $\mathrm{CERAD}=$ Consortium to Establish a Registry of Alzheimer's Disease; $\mathrm{Cl}=$ confidence interval; $F R E Q=$ frequent; $\mathrm{MMSE}=$ Mini-Mental State Examination; $\mathrm{MOD}=$ moderate; NA = not applicable; NFT = neurofibrillary tangle; NP = neuritic plaque. Estimates represent the unstandardized effect sizes (i.e., differences in trajectory slopes for each cognitive outcome and for each $A P O E$ genotype contrast). Model 1 is adjusted for age at death, sex, education, and Alzheimer disease neuropathological changes (CERAD NP score FREQ vs MOD and Braak NFT stage V/ VI vs III/IV). Model 2 is further adjusted for interaction terms between CERAD NP score or Braak NFT stage and the slope of cognitive trajectories and for concurrent pathologies.

for ADNC effects on rate of cognitive decline and these comorbid pathologies rendered somewhat different results, likely due to the confounding effects of the latter on different cognitive domains. Possession of an APOE $\varepsilon 4$ allele was associated with a significantly faster decline compared to the $A P O E \varepsilon 3 / \varepsilon 3$ reference group in only the memory and executive domains, whereas $A P O E \varepsilon 2$ carriers had a slower decline in language and executive functions than both $A P O E \varepsilon 3 / \varepsilon 3$ carriers and $A P O E \& 4$ carriers (table 3, figure 3, and figure e-1 available from Dryad). On the other hand, within 3 years before death, the $A P O E \& 2$ carriers declined significantly faster than the $A P O E \& 4$ and $A P O E \varepsilon 3 / \varepsilon 3$ carriers in the memory domain (table 4, figure 3 , and figure e-1 available from Dryad), likely reflecting a floor effect of the memory composite $z$ score in the last 2 groups at advanced dementia stages.

The goodness of fit of the proposed models for global cognitive measures (CDR-SOB and MMSE scores) and domain-specific composites was checked with the use of goodness-of-fit diagnostic graphs. Overall, we found that (1) the participant-specific residuals were approximately symmetric around zero; (2) the normal QQ plots of participantspecific residuals suggested that the residuals are normally distributed in most of their quantile range, and (3) in comparisons of the weighted predicted transformed cognitive outcome values averaged by time intervals along with the weighted average transformed observations, ${ }^{31}$ the individual predictions were close enough to the observations in the mixed-effects submodel (data not shown).

\section{Discussion}

In this large, national, clinicopathologic sample, selected to be representative of participants in clinical trials with biomarker- based eligibility criteria, we found a statistically significant difference in cognitive trajectory across $A P O E$ genotypes. In general, $A P O E \& 2$ carriers exhibited a slower decline and $A P O E \varepsilon 4$ carriers a faster decline than $A P O E \varepsilon 3 / \varepsilon 3$ carriers.

Our reverse longitudinal modeling approach enabled us to use information from patients with definite $\mathrm{AD}$, to control for neuropathologic comorbidities that may affect rate of progression, and to focus on the effect of APOE genotype. Previous disparate results on the cognitive impact of the $A P O E$ genotype may have reflected the lack of autopsy confirmation and noise introduced by variation in the extent and severity of $\mathrm{ADNC}$ and concurrent pathologies. ${ }^{6-15}$ Moreover, the 3-year change point is consistent with a prior report on the Religious Orders Study and Rush Memory and Aging Project (ROSMAP) cohort $^{36}$ and allowed us to identify and remove the expected ceiling/floor effects of cognitive outcome measures in advanced $\mathrm{AD}$ stages, providing data most relevant to mild and moderate dementia stages. Thus, our findings are consistent with a scenario in which the APOE 84 allele not only anticipates the onset of cognitive decline but also accelerates its progression later in the disease course, with the APOE $\varepsilon 2$ allele having opposite effects.

The magnitude of these differences approached clinical relevance even after controlling for the presence and severity of $\mathrm{ADNC}$ and concurrent pathologies (i.e., $\approx 0.7$ points of $\mathrm{CDR}$ SOB score per year and $\approx 0.5$ points of MMSE score per year in $A P O E$ \&4 carriers vs $A P O E \varepsilon 3 / \varepsilon 3$ carriers). Thus, our current results may help inform clinical trial design. While randomization would ensure matching of treatment and placebo groups by $A P O E$ genotype and APOE-based post hoc analyses are usual practice, ${ }^{37}$ stratification at enrollment by $A P O E$ genotype might be considered regardless of expected $A P O E$-driven differences in drug response or frequency of drug adverse effects. Some clinical trials have specified 

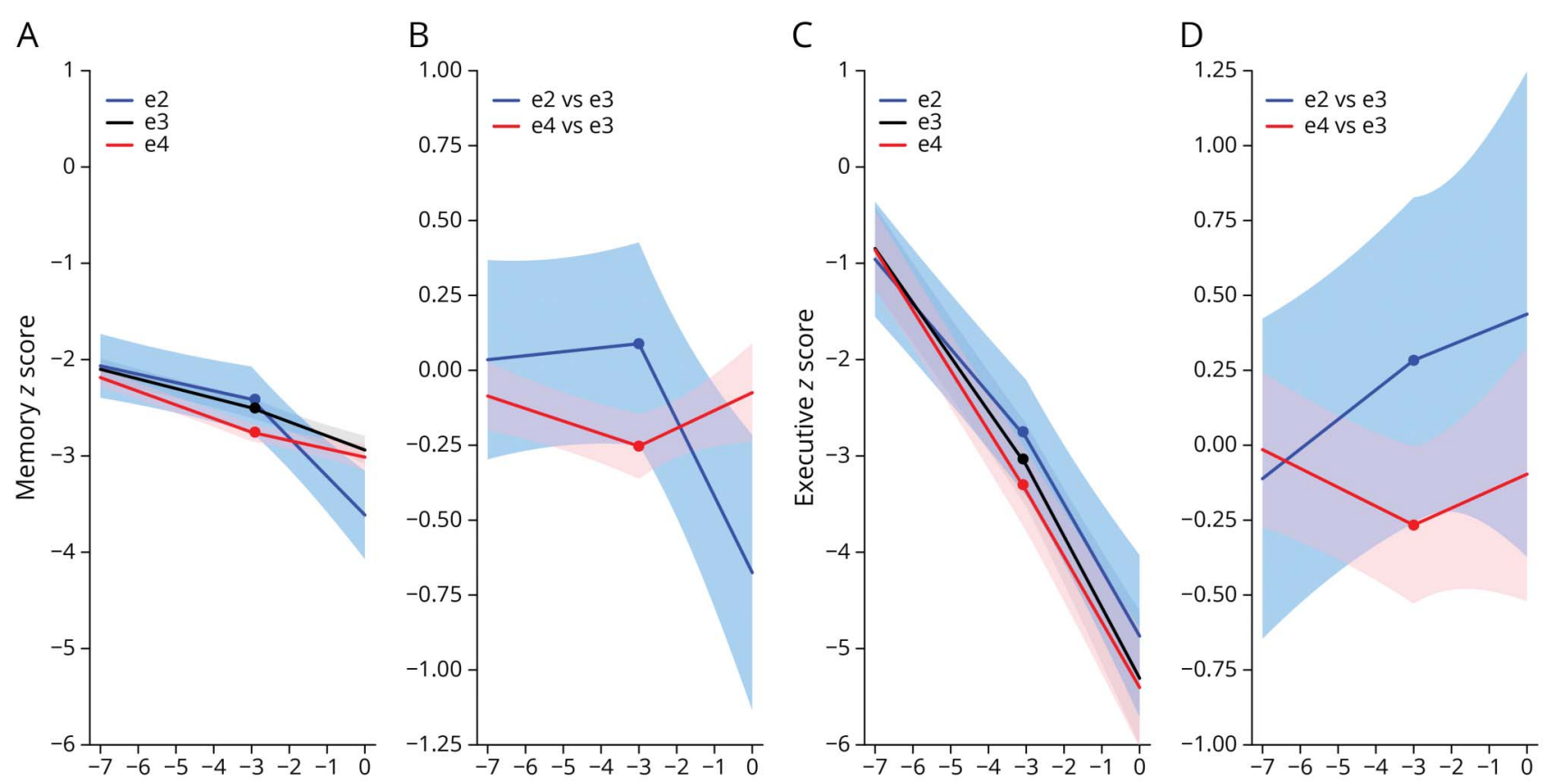

E

$\mathrm{F}$

G
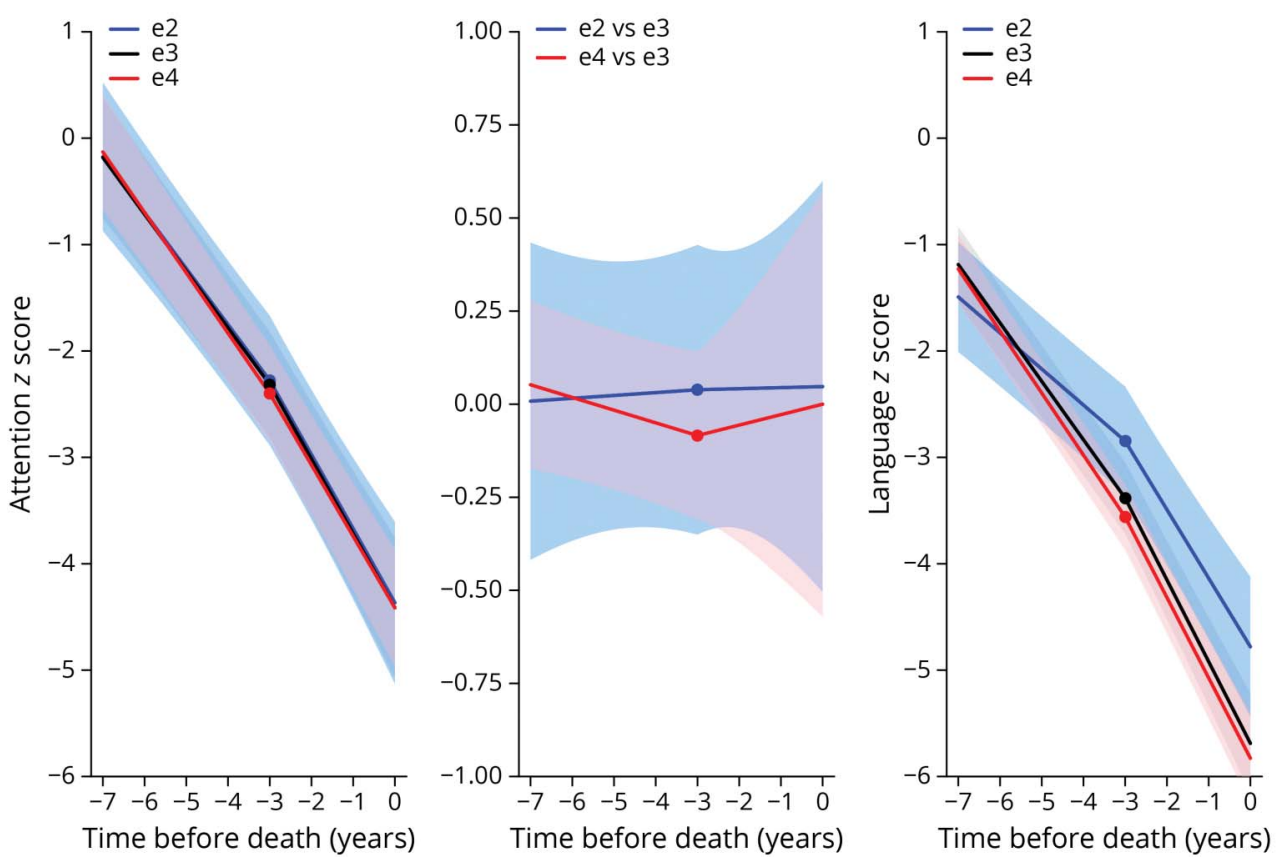

$\mathrm{H}$

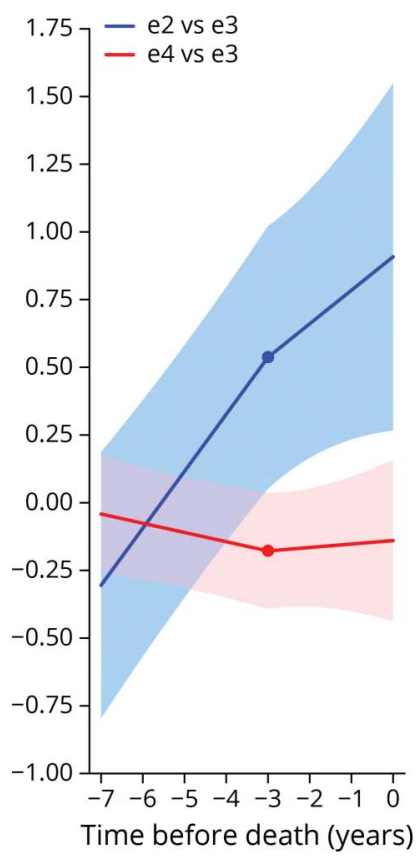

( $A, C, E$, and G) Model-based cognitive trajectories of (A) memory, (C) executive, (E) attention, and (G) language composite-measures z scores by APOE allele with the intercept at the time of death calculated for an 82-year-old woman with 15 years of education and autopsy findings of frequent Consortium to Establish a Registry of Alzheimer's Disease (CERAD) neuritic plaque score and Braak neurofibrillary tangle stage V/VI and no comorbid pathologies and with adjustments for the effect of Alzheimer disease neuropathologic variables (CERAD and Braak) on the rate of cognitive decline and for comorbid pathologies (model 2). (B, D, F, and H) Difference of model-based cognitive trajectories of (B) memory, (D) executive, (F) attention, and (H) language composite-measures z scores between $A P O E$ allele groups (APOE $\varepsilon 2$ and $A P O E \& 4$ VS APOE $\varepsilon 3 / \varepsilon 3$ carriers) under model 2 . Shaded areas represent the corresponding $95 \%$ confidence intervals.

alternative protocols for $A P O E \varepsilon 4$ carriers $^{38,39}$ because $A P O E$ $\varepsilon 4$ increases the risk of blood-brain barrier disruption caused by monoclonal anti-A $\beta$ antibodies leading to amyloid-related imaging abnormalities, ${ }^{40}$ which could in addition affect the relative rates of progression among treatment groups.
Moreover, although some of the concurrent pathologies controlled for here cannot be accurately ascertained antemortem, the data illustrate the importance of using available biomarkers to account for as many variables as possible in a clinical trial setting. 
Of note, our results are at odds with the hypothesis that the $A P O E$ genotype drives different $\mathrm{AD}$ clinical phenotypes, that is, an amnestic/temporo-limbic presentation in $A P O E \varepsilon 4$ carriers vs a dysexecutive/frontoparietal in $A P O E \quad \varepsilon 4$ noncarriers. ${ }^{41-43}$ APOE $\varepsilon 4$ carriers had a significantly faster decline in all cognitive domains examined (memory, attention, executive, and language) compared to $A P O E \varepsilon 3 / \varepsilon 3$ carriers in models not adjusted by $\mathrm{ADNC}$ effects on rate of cognitive decline and concurrent pathologies, and in both memory and executive function in adjusted models. Larger clinical and multimodal imaging studies including higher numbers of $A P O E \& 2$ carriers across $\mathrm{AD}$ preclinical and clinical stages are needed to confirm this hypothesis.

Our findings also provide important pathophysiologic insights. We were able to compare estimates between models with and without adjustment for the impact of $\mathrm{ADNC}$ on rate of cognitive decline and for comorbid pathologies. Overall, the results from both models were largely comparable: adjusting for interactions between $\mathrm{ADNC}$ and the slope of cognitive decline and for concurrent pathologies (model 2) rendered statistically significant point slope estimates that were only $3 \%$ to $24 \%$ smaller than those obtained without including these neuropathologic covariates (model 1), and some of the estimates for APOE $\varepsilon 2$ allele in model 2 were even larger than their counterparts in model 1 (table 3 ). Therefore, these results suggest that, relative to the APOE $\varepsilon 3$ allele, the $A P O E \& 2$ allele confers protection against cognitive decline beyond its known protective effects against $\mathrm{ADNC}$, whereas the $A P O E \& 4$ allele accelerates cognitive decline beyond its known promoting effects of $\mathrm{ADNC}$ and concurrent pathologies, that is, cerebrovascular disease, ${ }^{22} \mathrm{LB}$ disease, ${ }^{23}$ and transactive response DNA-binding protein $43 \mathrm{kDa}$ (TDP-43) proteinopathy $^{24}$ (controlled here by the presence/absence of $\mathrm{HScl}$ ). The cognitive protective effects of the APOE $\varepsilon 2$ allele observed in this moderate/high ADNC sample are reminiscent of the cognitive resilience to $\mathrm{ADNC}$ recently reported for both the Christchurch homozygous mutation in the APOE gene ${ }^{44}$ and $A P O E \varepsilon 2$ homozygosity. ${ }^{45}$ Multiple $A \beta$-dependent and -independent mechanisms could explain these APOEmediated differences in cognitive decline rate: impaired glucose utilization ${ }^{46}$; stabilization of synaptotoxic $A \beta$ oligomers $^{47}$; increased colocalization of $A \beta$ oligomers with synapses ${ }^{48}$; altered synaptic pruning ${ }^{49}$; exacerbated microglial inflammation, tau spreading, and neurodegeneration ${ }^{9,50}$; and impaired neuroprotective mechanisms. ${ }^{51}$

Some limitations of our study pertinent to available or collected data should be acknowledged. This moderate/high ADNC sample is not suited to capture possible differences in rate of cognitive decline or phenotypic presentation differences across $A P O E$ genotypes at the earliest clinical stages. Thus, our study participants do not resemble those enrolled in current therapeutic clinical trials targeting subjective or very mild cognitive impairment or in secondary prevention trials (i.e., cognitively intact individuals with positive $\mathrm{AD}$ biomarkers). The underrepresentation of $A P O E \varepsilon 2$ carriers with substantial ADNC $(n=44)$ is expected given the protective effect of this allele against $\mathrm{AD}$; $A P O E \varepsilon 4$ carriers would also be underrepresented in a sample of cognitively intact individuals with low ADNC., ${ }^{5,45}$ In addition, the effects of APOE genotype on the visuospatial/perceptive domain could not be studied due to insufficient specific neuropsychological tests for these skills in the first 2 NACC UDS iterations, ${ }^{26}$ and we had to use the presence of $\mathrm{HScl}$ as an imperfect surrogate of TDP-43 pathology because this has been recorded only since January 2014. ${ }^{52}$ Other limitations concern the statistical modeling. To be able to use the autopsy variables as baseline covariates and to apply reverse longitudinal modeling, we assumed that amyloid plaque burden plateaus early in the clinical course of $\mathrm{AD}$ and that the sequence of Braak NFT stages from limbic (III/IV) to neocortical (V/VI) is valid over the extent of the follow-up; these assumptions are well supported by prior A $\beta$ and tau PET imaging studies. ${ }^{34,35}$ The complexity of our modeling strategy prevented us from including some terms in the models due to risk of overfitting such as a participant-specific change point as a random variable and interaction terms between $A P O E$ genotype and comorbid pathologies or between comorbid pathologies and slope of cognitive decline.

The APOE $\varepsilon 2$ and $A P O E \varepsilon 4$ alleles have opposing effects on the rate of cognitive decline compared to the most common $A P O E \varepsilon 3 / \varepsilon 3$ genotype. These effects are clinically relevant, detectable in samples comparable in size and demographics to those enrolled in prototypical clinical trials, and largely independent of their known effects on measured ADNC and comorbid pathologies. Thus, besides neuropathology, other $A P O E$-related phenotypes - perhaps microglial and astrocytic reactions ${ }^{9,49,50}$ — might drive $\mathrm{AD}$ clinical progression. Further research to understand this $A P O E \& 2-$ mediated resilience and APOE $\varepsilon 4$-linked adversity is warranted.

\section{Study Funding}

J. Qian received research support from the National Institute of Neurological Disorders and Stroke (NINDS) (R01NS094610) and National Institute on Aging (NIA) (R21AG053695). R.A. Betensky received research support from NINDS (R01NS094610) and NIA (P30AG06651201 and R21AG053695). B.T. Hyman received research support from NIA (P30 AG062421-01). A. Serrano-Pozo received research support from NINDS (R25NS065743), NIA (K08AG064039), and the Alzheimer's Association (AACF-17-524184). The NACC database is funded by NIA/NIH grant U01 AG016976. NACC data are contributed by the NIA-funded ADCs: P30 AG019610 (principal investigator [PI] Eric Reiman, MD), P30 AG013846 (PI Neil Kowall, MD), P30 AG062428-01 (PI James Leverenz, MD), P50 AG008702 (PI Scott Small, MD), P50 AG025688 (PI Allan Levey, MD, PhD), P50 AG047266 (PI Todd Golde, MD, PhD), P30 AG010133 (PI Andrew Saykin, PsyD), P50 AG005146 (PI Marilyn Albert, PhD), P30 AG062421-01 (PI Bradley Hyman, MD, PhD), P30 
AG062422-01 (PI Ronald Petersen, MD, PhD), P50 AG005138 (PI Mary Sano, PhD), P30 AG008051 (PI Thomas Wisniewski, MD), P30 AG013854 (PI Robert Vassar, PhD), P30 AG008017 (PI Jeffrey Kaye, MD), P30 AG010161 (PI David Bennett, MD), P50 AG047366 (PI Victor Henderson, MD, MS), P30 AG010129 (PI Charles DeCarli, MD), P50 AG016573 (PI Frank LaFerla, PhD), P30 AG062429-01 (PI James Brewer, MD, PhD), P50 AG023501 (PI Bruce Miller, MD), P30 AG035982 (PI Russell Swerdlow, MD), P30 AG028383 (PI Linda Van Eldik, PhD), P30 AG053760 (PI Henry Paulson, MD, PhD), P30 AG010124 (PI John Trojanowski, MD, PhD), P50 AG005133 (PI Oscar Lopez, MD), P50 AG005142 (PI Helena Chui, MD), P30 AG012300 (PI Roger Rosenberg, MD), P30 AG049638 (PI Suzanne Craft, PhD), P50 AG005136 (PI Thomas Grabowski, MD), P30 AG06271501 (PI Sanjay Asthana, MD, FRCP), P50 AG005681 (PI John Morris, MD), and P50 AG047270 (PI Stephen Strittmatter, MD PhD). The authors express their gratitude to the participants and informants involved in research at the US Alzheimer Disease Research Centers.

\section{Disclosure}

B.T. Hyman has a family member who works at Novartis and owns stock in Novartis; he serves on the scientific advisory board of Dewpoint and owns stock; he serves on a scientific advisory board or is a consultant for Abbvie, Arvinas, Biogen, Novartis, Cell Signaling, the US Department of Justice, Takeda, Vigil, W20 group, and Seer; and his laboratory is supported by sponsored research agreements with Abbvie, Amgen, Arvinas, Biogen, Denali, Dewpoint, Fidelity Biosciences, F Prime, General Electric, Eli Lilly, Merck, Sangamo, and Spark, as well as research grants from the NIH (PI), Cure Alzheimer's Fund (PI), Tau Consortium (PI), the JPB Foundation (PI), Alzheimer's Association (mentor), and Brightfocus (mentor). R.A. Betensky serves on the National Cancer Institute Board of Scientific Counselors for Clinical Sciences and Epidemiology, Biogen, Alexion, Reata, and PTC Therapeutics; she is consultant for Cowen Inc and has served as expert witness for Amarin, Actavis, Amazon, and Apotex and as consultant for Pfizer and Amgen. Drs. Qian and Serrano-Pozo have no disclosures. Go to Neurology.org/N for full disclosures.

\section{Publication History}

Received by Neurology July 29, 2020. Accepted in final form February 12, 2021.

Appendix Authors

\begin{tabular}{lll}
\hline Name & Location & Contribution \\
\hline Jing Qian, PhD & $\begin{array}{l}\text { University of } \\
\text { Massachusetts, } \\
\text { Amherst }\end{array}$ & $\begin{array}{l}\text { Analyzed and interpreted the data, } \\
\text { performed statistical analysis, } \\
\text { revised the manuscript for } \\
\text { intellectual content }\end{array}$ \\
\hline
\end{tabular}

Appendix (continued)

\begin{tabular}{lll}
\hline Name & Location & Contribution \\
\hline $\begin{array}{l}\text { Rebecca A. } \\
\text { Betensky, PhD }\end{array}$ & $\begin{array}{l}\text { New York } \\
\text { University, New } \\
\text { York City }\end{array}$ & $\begin{array}{l}\text { Designed the study, interpreted } \\
\text { the data, performed statistical } \\
\text { analysis, revised the manuscript } \\
\text { for intellectual content }\end{array}$ \\
$\begin{array}{l}\text { Bradley T. } \\
\text { Hyman, MD, } \\
\text { PhD }\end{array}$ & $\begin{array}{l}\text { Massachusetts } \\
\text { Beneral Hospital, }\end{array}$ & $\begin{array}{l}\text { Designed the study, interpreted } \\
\text { the data, revised the manuscript } \\
\text { for intellectual content }\end{array}$ \\
$\begin{array}{l}\text { Alberto } \\
\text { Serrano-Pozo, } \\
\text { MD, PhD }\end{array}$ & $\begin{array}{l}\text { General Hospital, } \\
\text { Boston }\end{array}$ & $\begin{array}{l}\text { Conceptualized and designed the } \\
\text { study, interpreted the data, } \\
\text { drafted the manuscript for } \\
\text { intellectual content }\end{array}$ \\
\hline
\end{tabular}

\section{References}

1. Sperling RA, Rentz DM, Johnson KA, et al. The A4 Study: stopping AD before symptoms begin? Sci Transl Med 2014;6:228fs13.

2. Corder EH, Saunders AM, Strittmatter WJ, et al. Gene dose of apolipoprotein E type 4 allele and the risk of Alzheimer's disease in late onset families. Science 1993;261: 921-923.

3. Corder EH, Saunders AM, Risch NJ, et al. Protective effect of apolipoprotein E type 2 allele for late onset Alzheimer disease. Nat Genet 1994;7:180-184.

4. Bennett DA, Wilson RS, Schneider JA, et al. Apolipoprotein E epsilon4 allele, AD pathology, and the clinical expression of Alzheimer's disease. Neurology 2003;60: $246-252$.

5. Serrano-Pozo A, Qian J, Monsell SE, Betensky RA, Hyman BT. APOE\&2 is associated with milder clinical and pathological Alzheimer disease. Ann Neurol 2015;77: 917-929.

6. Wilson RS, Schneider JA, Barnes LL, et al. The apolipoprotein E epsilon 4 allele and decline in different cognitive systems during a 6-year period. Arch Neurol 2002;59: 1154-1160.

7. Martins CAR, Oulhaj A, de Jager CA, Williams JH. APOE alleles predict the rate of cognitive decline in Alzheimer disease: a nonlinear model. Neurology 2005;65: 1888-1893.

8. Cosentino S, Scarmeas N, Helzner E, et al. APOE epsilon 4 allele predicts faster cognitive decline in mild Alzheimer disease. Neurology 2008;70:1842-1849.

9. Shi Y, Yamada K, Liddelow SA, et al. ApoE4 markedly exacerbates tau-mediated neurodegeneration in a mouse model of tauopathy. Nature 2017;549:523-527.

10. Gomez-Isla T, West HL, Rebeck GW, et al. Clinical and pathological correlates of apolipoprotein E epsilon 4 in Alzheimer's disease. Ann Neurol 1996;39:62-70.

11. Dal Forno G, Rasmusson DX, Brandt J, et al. Apolipoprotein E genotype and rate of decline in probable Alzheimer's disease. Arch Neurol 1996;53:345-350.

12. Bunce D, Fratiglioni L, Small BJ, Winblad B, Bäckman L. APOE and cognitive decline in preclinical Alzheimer disease and non-demented aging. Neurology 2004;63: 816-821.

13. Stern Y, Brandt J, Albert M, et al. The absence of an apolipoprotein epsilon4 allele is associated with a more aggressive form of Alzheimer's disease. Ann Neurol 1997;41: 615-620.

14. Hoyt BD, Massman PJ, Schatschneider C, Cooke N, Doody RS. Individual growth curve analysis of APOE epsilon 4-associated cognitive decline in Alzheimer disease. Arch Neurol 2005;62:454-459.

15. van der Vlies AE, Koedam ELGE, Pijnenburg YAL, Twisk JWR, Scheltens P, van der Flier WM. Most rapid cognitive decline in APOE epsilon4 negative Alzheimer's disease with early onset. Psychol Med 2009;39:1907-1911.

16. Wilson RS, Bienias JL, Berry-Kravis E, Evans DA, Bennett DA. The apolipoprotein E epsilon 2 allele and decline in episodic memory. J Neurol Neurosurg Psychiatry 2002; 73:672-677.

17. Bonner-Jackson A, Okonkwo O, Tremont G; Alzheimer's Disease Neuroimaging Initiative. Apolipoprotein E $\varepsilon 2$ and functional decline in amnestic mild cognitive impairment and Alzheimer disease. Am J Geriatr Psychiatry 2012;20:584-593.

18. Shinohara M, Kanekiyo T, Yang L, et al. APOE2 eases cognitive decline during aging: clinical and preclinical evaluations. Ann Neurol 2016;79:758-774.

19. Beach TG, Monsell SE, Phillips LE, Kukull W. Accuracy of the clinical diagnosis of Alzheimer disease at National Institute on Aging Alzheimer Disease Centers, 20052010. J Neuropathol Exp Neurol 2012;71:266-273.

20. Serrano-Pozo A, Qian J, Monsell SE, et al. Mild to moderate Alzheimer dementia with insufficient neuropathological changes. Ann Neurol 2014;75:597-601.

21. Boyle PA, Yu L, Leurgans SE, et al. Attributable risk of Alzheimer's dementia attributed to age-related neuropathologies. Ann Neurol 2019;85:114-124.

22. Montagne A, Nation DA, Sagare AP, et al. APOE4 leads to blood-brain barrier dysfunction predicting cognitive decline. Nature 2020;581:71-76.

23. Dickson DW, Heckman MG, Murray ME, et al. APOE $\varepsilon 4$ is associated with severity of Lewy body pathology independent of Alzheimer pathology. Neurology 2018;91: e1182-e1195. 
24. Yang HS, Yu L, White CC, et al. Evaluation of TDP-43 proteinopathy and hippocampal sclerosis in relation to APOE $\varepsilon 4$ haplotype status: a community-based cohort study. Lancet Neurol 2018;17:773-781.

25. Besser L, Kukull W, Knopman DS, et al. Version 3 of the National Alzheimer's Coordinating Center's Uniform Data Set. Alzheimer Dis Assoc Disord 2018;32:351-358.

26. Weintraub S, Besser L, Dodge HH, et al. Version 3 of the Alzheimer Disease Centers' neuropsychological test battery in the Uniform Data Set (UDS). Alzheimer Dis Assoc Disord 2018;32:10-17.

27. Montine TJ, Phelps CH, Beach TG, et al. National Institute on Aging-Alzheimer's Association guidelines for the neuropathologic assessment of Alzheimer's disease: a practical approach. Acta Neuropathol (Berl) 2012;123:1-11.

28. Clark CM, Pontecorvo MJ, Beach TG, et al. Cerebral PET with florbetapir compared with neuropathology at autopsy for detection of neuritic amyloid- $\beta$ plaques: a prospective cohort study. Lancet Neurol 2012;11:669-678.

29. Marquié M, Siao Tick Chong M, Antón-Fernández A, et al. [F-18]-AV-1451 binding correlates with postmortem neurofibrillary tangle Braak staging. Acta Neuropathol (Berl) 2017;134:619-628.

30. Serrano-Pozo A, Qian J, Monsell SE, Frosch MP, Betensky RA, Hyman BT. Examination of the clinicopathologic continuum of Alzheimer disease in the autopsy cohort of the National Alzheimer Coordinating Center. J Neuropathol Exp Neurol 2013;72:1182-1192.

31. Proust-Lima C, Philipps V, Liquet B. Estimation of extended mixed models using latent classes and latent processes: the $R$ package $\mathrm{lcmm}$. J Stat Softw 2017;78.Available at jstatsoft.org/v78/i02/. Accessed December 21, 2020.

32. Hayden KM, Jones RN, Zimmer C, et al. Factor structure of the National Alzheimer's Coordinating Centers Uniform Dataset Neuropsychological Battery: an evaluation of invariance between and within groups over time. Alzheimer Dis Assoc Disord 2011; 25:128-137.

33. Qian J, Hyman BT, Betensky RA. Neurofibrillary tangle stage and the rate of progression of Alzheimer symptoms: modeling using an autopsy cohort and application to clinical trial design. JAMA Neurol 2017;74:540-548.

34. Jack CR, Wiste HJ, Lesnick TG, et al. Brain $\beta$-amyloid load approaches a plateau. Neurology 2013;80:890-896.

35. Schöll M, Lockhart SN, Schonhaut DR, et al. PET imaging of tau deposition in the aging human brain. Neuron 2016;89:971-982.

36. Yu L, Boyle P, Schneider JA, et al. APOE $\varepsilon 4$, Alzheimer's disease pathology, cerebrovascular disease, and cognitive change over the years prior to death. Psychol Aging 2013;28:1015-1023.

37. Kennedy RE, Cutter GR, Schneider LS. Effect of APOE genotype status on targeted clinical trials outcomes and efficiency in dementia and mild cognitive impairment resulting from Alzheimer's disease. Alzheimers Dement 2014;10:349-359.

38. Salloway S, Sperling R, Fox NC, et al. Two phase 3 trials of bapineuzumab in mild-tomoderate Alzheimer's disease. N Engl J Med 2014;370:322-333.
39. Sevigny $\mathrm{J}$, Chiao $\mathrm{P}$, Bussière $\mathrm{T}$, et al. The antibody aducanumab reduces $\mathrm{A} \beta$ plaques in Alzheimer's disease. Nature 2016;537:50-56.

40. Sperling RA, Jack CR, Black SE, et al. Amyloid-related imaging abnormalities in amyloid-modifying therapeutic trials: recommendations from the Alzheimer's Association Research Roundtable Workgroup. Alzheimers Dement 2011;7:367-385.

41. van der Flier WM, Schoonenboom SNM, Pijnenburg YAL, Fox NC, Scheltens P. The effect of APOE genotype on clinical phenotype in Alzheimer disease. Neurology 2006;67:526-527.

42. Wolk DA, Dickerson BC. Alzheimer's Disease Neuroimaging Initiative. Apolipoprotein $\mathrm{E}$ (APOE) genotype has dissociable effects on memory and attentionalexecutive network function in Alzheimer's disease. Proc Natl Acad Sci USA 2010;107: 10256-10261.

43. Dickerson BC, Wolk DA. Alzheimer's Disease Neuroimaging Initiative. Dysexecutive versus amnesic phenotypes of very mild Alzheimer's disease are associated with distinct clinical, genetic and cortical thinning characteristics. J Neurol Neurosurg Psychiatry $2011 ; 82: 45-51$.

44. Arboleda-Velasquez JF, Lopera F, O'Hare M, et al. Resistance to autosomal dominant Alzheimer's disease in an APOE3 Christchurch homozygote: a case report. Nat Med 2019;25:1680-1683.

45. Reiman EM, Arboleda-Velasquez JF, Quiroz YT, et al. Exceptionally low likelihood of Alzheimer's dementia in APOE2 homozygotes from a 5,000-person neuropathological study. Nat Commun 2020;11:667.

46. Mosconi L, Nacmias B, Sorbi S, et al. Brain metabolic decreases related to the dose of the ApoE e4 allele in Alzheimer's disease. J Neurol Neurosurg Psychiatry 2004;75: 370-376.

47. Hashimoto T, Serrano-Pozo A, Hori Y, et al. Apolipoprotein E, especially apolipoprotein E4, increases the oligomerization of amyloid $\beta$ peptide. J Neurosci 2012;32: $15181-15192$.

48. Koffie RM, Hashimoto T, Tai HC, et al. Apolipoprotein E4 effects in Alzheimer's disease are mediated by synaptotoxic oligomeric amyloid- $\beta$. Brain J Neurol 2012;135: 2155-2168.

49. Chung WS, Verghese PB, Chakraborty C, et al. Novel allele-dependent role for APOE in controlling the rate of synapse pruning by astrocytes. Proc Natl Acad Sci USA 2016; 113:10186-10191.

50. Lin YT, Seo J, Gao F, et al. APOE4 causes widespread molecular and cellular alterations associated with Alzheimer's disease phenotypes in human iPSC-derived brain cell types. Neuron 2018;98:1141-1154.e7.

51. Zhao J, Davis MD, Martens YA, et al. APOE $\varepsilon 4 / \varepsilon 4$ diminishes neurotrophic function of human iPSC-derived astrocytes. Hum Mol Genet 2017;26:2690-2700.

52. Besser LM, Kukull WA, Teylan MA, et al. The revised National Alzheimer's Coordinating Center's Neuropathology form: available data and new analyses. J Neuropathol Exp Neurol 2018;77:717-726. 


\section{Neurology}

\section{Association of APOE Genotype With Heterogeneity of Cognitive Decline Rate in Alzheimer Disease}

Jing Qian, Rebecca A. Betensky, Bradley T. Hyman, et al.

Neurology 2021;96;e2414-e2428 Published Online before print March 26, 2021

DOI 10.1212/WNL.0000000000011883

\section{This information is current as of March 26, 2021}

\section{Updated Information \&} Services

References

Subspecialty Collections

Permissions \& Licensing

Reprints including high resolution figures, can be found at: http://n.neurology.org/content/96/19/e2414.full

This article cites 51 articles, 15 of which you can access for free at: http://n.neurology.org/content/96/19/e2414.full\#ref-list-1

This article, along with others on similar topics, appears in the following collection(s):

Alzheimer's disease

http://n.neurology.org/cgi/collection/alzheimers_disease Neuropsychological assessment

http://n.neurology.org/cgi/collection/neuropsychological_assessment

Information about reproducing this article in parts (figures,tables) or in its entirety can be found online at:

http://www.neurology.org/about/about_the_journal\#permissions

Information about ordering reprints can be found online:

http://n.neurology.org/subscribers/advertise

Neurology ${ }^{\circledR}$ is the official journal of the American Academy of Neurology. Published continuously since 1951, it is now a weekly with 48 issues per year. Copyright Copyright $\odot 2021$ The Author(s). Published by Wolters Kluwer Health, Inc. on behalf of the American Academy of Neurology.. All rights reserved. Print ISSN: 0028-3878. Online ISSN: 1526-632X.

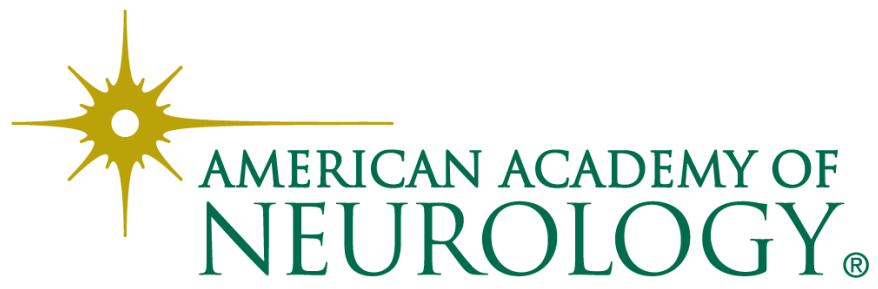

